\title{
Chromogranin A as circulating marker for diagnosis and management of neuroendocrine neoplasms: more flaws than fame
}

\author{
Vincenzo Marotta1,*, Maria Chiara Zatelli2,*, Concetta Sciammarella3, Maria Rosaria Ambrosio², Marta Bondanelli2, \\ Annamaria Colao' and Antongiulio Faggiano ${ }^{4}$
}

1Department of Clinical Medicine and Surgery, Federico II University, Naples, Italy

2Section of Endocrinology and Internal Medicine, Department of Medical Sciences, University of Ferrara, Ferrara, Italy

IIOS \& COLEMAN Srl, Naples, Italy

${ }^{4}$ Thyroid and Parathyroid Surgery Unit, Istituto Nazionale per lo Studio e la Cura dei Tumori 'Fondazione G. Pascale' - IRCCS, Naples, Italy

Correspondence should be addressed to V Marotta: vinc.endo@libero.it

*(V Marotta and M C Zatelli contributed equally to this work)

\begin{abstract}
Owing to the heterogeneity of neuroendocrine neoplasms (NENs), the availability of reliable circulating markers is critical for improving diagnostics, prognostic stratification, follow-up and definition of treatment strategy. This review is focused on chromogranin A (CgA), a hydrophilic glycoprotein present in large dense core vesicles of neuroendocrine cells. Despite being long identified as the most useful NEN-related circulating marker, clinical application of $\mathrm{CgA}$ is controversial. CgA assays still lack standardization, thus hampering not only clinical management but also the comparison between different analyses. In the diagnostic setting, clinical utility of $\mathrm{CgA}$ is limited as hampered by (a) the variety of oncological and non-oncological conditions affecting marker levels, which impairs specificity; (b) the fact that $30-50 \%$ of NENs show normal CgA, which impairs sensitivity. Regarding the prognostic phase, there is prospective evidence which demonstrates that advanced NENs secreting CgA have poorer outcome, as compared with those showing non-elevated marker levels. Although the identification of cut-offs allowing a proper risk stratification of $\mathrm{CgA}$-secreting patients has not been performed, this represents the most important clinical application of the marker. By contrast, based on prospective studies, the trend of elevated circulating $\mathrm{CgA}$ does not represent a valid indicator of morphological evolution and has therefore no utility for the follow-up phase. Ultimately, current knowledge about the role of the marker for the definition of treatment strategy is poor and is limited by the small number of available studies, their prevalent retrospective nature and the absence of control groups of untreated subjects.
\end{abstract}

Endocrine-Related Cancer (2018) 25, R11-R29

\section{Introduction}

Despite being rare diseases, neuroendocrine neoplasms (NENs) have shown a worldwide increase in the past several decades, with incidence rates rising from 1.52 to
7.41 cases per 100,000 from 1973 to 2012 (Leoncini et al. 2017). Therefore, physicians dealing with NENs urgently need better guidance as to clinical management, which is

\section{Key Words}

- chromogranin A

- neuroendocrine neoplasm

- biomarker

- diagnosis

- prognosis

- response to treatment 
still empiric (Faggiano et al. 2012, Oberg 2012). Actually, the definition of NENs gathers a heterogeneous group of diseases, including malignancies from several anatomic areas, such as stomach, intestine, rectum, pancreas, lung, adrenals and thyroid, and with variable evolution, from indolent to rapidly progressive (Baudin 2007, Yao et al. 2008a). The feature joining these tumors is that they arise from specialized cells spread throughout the body, belonging to the so-called diffuse neuroendocrine system, whose main ability is to produce, store and release the bloodstream bioactive molecules (Langley 1994, Kaltsas et al. 2004, Ferolla et al. 2008). Whether this biological activity produces characteristic syndromes represents the major factor affecting clinical scenario of NENs, which are accordingly classified into functional and nonfunctional (Kulke et al. 2012). Indeed, the former ones are usually diagnosed at an earlier stage because of endocrine symptoms related to the hormonal production, whereas the non-functional ones remain silent for large part of their natural history and are frequently diagnosed when metastases have already occurred (Modlin et al. 2008). Owing to these observations, a possible clinical application of tumor-related bioactive products, as detected in the serum or plasma, has represented the objective of a wide body of research. Particularly, researchers aimed to identify markers useful for (a) diagnosis anticipation and refining, (b) prognostic stratification and (c) disease evolution monitoring and response to treatment. Based on the relationship with codified hormone-related syndromes, circulating markers of NEN are differentiated in common or broad spectrum, including chromogranin A (CgA), pancreatic polypeptide and neuron-specific enolase, and specific or individual, including serotonin and its metabolite 5-hydroxyindolylacetic acid, gastrin, glucagon, insulin, C-peptide, vasoactive intestinal peptide, somatostatin, histamine, calcitonin, parathyroid, somatotropic, adrenocorticotropic hormones, catecholamines and their metabolites and neuropeptides (Ferolla et al. 2008). The present review is focused on CgA, a hydrophilic glycoprotein abundantly expressed in large dense core vesicles of neuroendocrine cells, whose main biological role is to regulate calcium-mediated exocytosis (Borges et al. 2010). Consistent with the definition of a common marker, elevated levels of circulating CgA have been associated with almost all types of NEN, including those arising from the gastroenteropancreatic tract and the bronchopulmonary area, which represent the majority, but also pheocromocytomas/paragangliomas, medullary thyroid carcinoma, Merkel cell carcinoma of the skin and (even if data are controversial) pituitary and parathyroid adenomas (Sobol et al. 1986, Blind et al. 1992, Kimura et al. 1997, Nobels et al. 1997, Guignat et al. 2001, Tomassetti et al. 2001b, Campana et al. 2007, Zatelli et al. 2007). Despite having a long recognized role for the histological definition of NEN (Solcia et al. 2000), actual use of $\mathrm{CgA}$ as a circulating marker is far more tricky than expected (Modlin et al. 2014c). Indeed, the clinical utility of the test is affected by a variety of issues, which will be strictly analyzed in our review.

\section{CgA physiology: production and biological functions}

CgA belongs to the granin family, which also includes chromogranin B, secretogranins II and III and other proteins (7B2, NESP55, proSAAS and VGF). All of them are involved in a series of biological pathways controlling protein (peptides, hormones, neurotransmitters and growth factors) secretion upon secretagogue stimulation (Arvan et al. 1991). Besides being stored into secretory vesicles, the members of the granin family have many common properties, such as a similar acidic isoelectric point, the capacity to bind calcium ions and the ability to form aggregates. Furthermore, their structure typically includes multiple dibasic cleavage sites, which allow the processing into smaller peptides, each displaying a differential function (O'Connor \& Frigon 1984, Gerdes et al. 1988, Borges et al. 2010, Mahata et al. 2010, SanchezMargalet et al. 2010, Helle \& Corti 2015). Human CgA is encoded by the CHGA gene, located on chromosome 14q32.12. This 12.192 base-pair-long gene, encompassing 8 exons and 7 introns, is transcribed into a 2.041 base-pairlong mRNA, which is in turn translated into a 439-aminoacid mature protein (Winkler \& Fischer-Colbrie 1992) showing 10 dibasic sites for proteolytic cleavage (Konecki et al. 1987). CgA-derived peptides include vasostatins (VST I: hCgA1-76 and VST II: hCgA1-115) (Aardal et al. 1993), pancreastatin (PST: hCgA357-428) (Tatemoto et al. 1986), catestatin (CST: hCgA352-372) (Mahata et al. 1997), a 14-amino-acid peptide with N-terminal tryptophan and C-terminal glutamic acid (hCgA324-337) and serpinin (bCgA 403-428) (Koshimizu et al. 2010). As shown in Fig. $1, \mathrm{CgA}$ is synthesized at the rough endoplasmic reticulum, where it is inserted via the N-terminal signal peptide, and then transported to the Golgi complex (Kuehn et al. 1998). CgA is then packaged together with other secretory proteins (i.e. hormones and peptides) into immature granules, where it may be cleaved into the various derived peptides by specific processing enzymes. Upon acidification, secretory granules mature, thus 


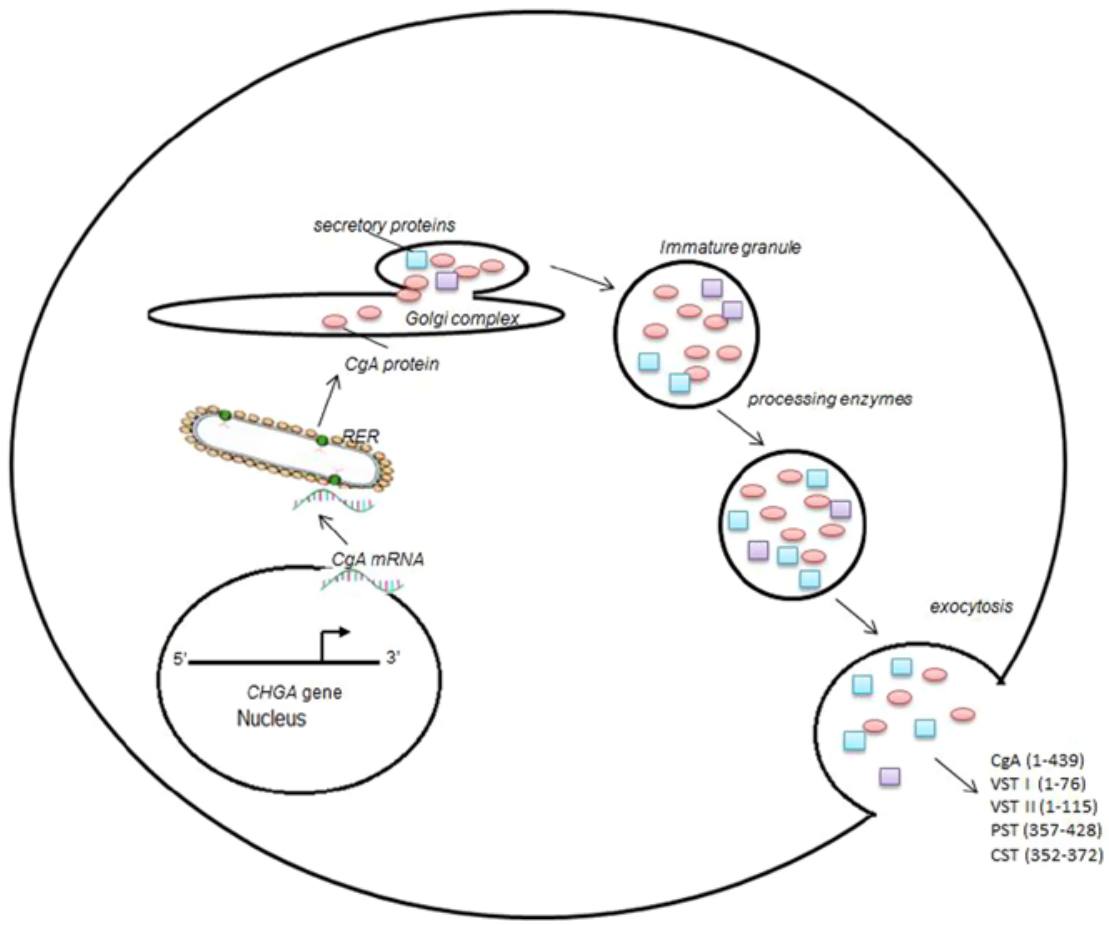

Figure 1

Physiology of production and secretion of $\mathrm{CgA}$ and related products. becoming ready for stimulation-induced release (Kim et al. 2006). CgA and the derived peptides display several biological functions. VST I (1-76) and VST II (1-115) have vasodilator and antimicrobial properties. VST I has also been demonstrated to inhibit PTH secretion, promote cell adhesion and inhibit VEGF-induced endothelial cell proliferation/migration (Ferrero et al. 2004, Blois et al. 2006, Belloni et al. 2007). Furthermore, it promotes calcium entry into neutrophils (Zhang et al. 2009), indicating an immune-endocrine crosstalk. PST (357-428) induces hyperglycemia by inhibiting glucose-stimulated insulin release from $\beta$-cells (Tatemoto et al. 1986) and glucose uptake in adipocytes and hepatocytes (Gonzalez-Yanes \& Sanchez-Margalet 2000) and by stimulating glucagon secretion and glycogenolysis (Sanchez-Margalet et al. $1992 a, b)$. In addition, it inhibits PTH release and stimulates histamine release. CST (352-372) is a potent endogenous antagonist of the nicotinic cholinergic receptor, being able to inhibit nicotine-induced catecholamine secretion (Mahata et al. 1997, Mahata et al. 2004). CST has also been demonstrated to inhibit lypolysis and fatty acid oxidation by regulating adrenergic and leptin signaling (Borges et al. 2013). Due to its capacity to stimulate histamine release, CST acts as a potent vasodilator (Kruger et al. 2003). Furthermore, it was found to induce endothelial cell proliferation/migration and to reduce cardiac contractility. Intact CgA (1-439) controls dense core granule biogenesis as well as sorting and secretion of other proteins. Specifically, it prevents uncontrolled osmotic swelling of secretory vesicles, functioning as a matrix condenser for soluble intra-vesicular component (Borges et al. 2013). CgA has been demonstrated to participate in the regulation of cytosolic calcium stores, granule exocytosis in secretory cells (Yoo 2010, Yoo et al. 2010) and prohormone convertase activity. In addition, it is involved in blood pressure regulation through the stimulation of the sympathetic tone (Takiyyuddin et al. 1991, Dimsdale et al. 1992). Notably, CgA processing into CST induces opposite effects on blood pressure, since CST inhibits catecholamine secretion (as already discussed). This is a paradigm of the complexity of biological effects related to $\mathrm{CgA}$, which depends on the balance between the intact and the cleaved protein.

\section{Methods for circulating CgA determination}

$\mathrm{CgA}$ detection is based on different assays, which are non-standardized and provide different information. This hampers both clinical management, where the same assay should be used from diagnosis to follow-up of each patients, and also comparison between different studies.

The assessment of circulating CgA levels can be performed by several commercially available kits, which differ in methodology but all rely on antibody-dependent assayssuch asenzyme-linkedimmunosorbentassay(ELISA), immunoradiometric assay (IRMA), radioimmunoassay 
(RIA) and the more recent immunofluorescent assay based on Time-Resolved Amplified Cryptate Emission (TRACE). Recently, a further method has been described: Minamiki et al. (2016) demonstrated highly sensitive CgA detection by means of an extended-gated organic-fieldeffect-transistor-based immunosensor, which employed a non-labeled monoclonal anti-CgA antibody. CgA may be assessed in plasma or serum, depending on the assay. Actually, a study by Woltering et al. (2006) showed that plasma and serum CgA levels, both measured by a twosite chemiluminescence immunometric assay using a biotinylated monoclonal antibody, displayed strong positive linear correlation $(r=0.9858, P<0.0001)$, thus suggesting that the measurement could be performed in both sample types with consistent results. Although plasma CgA levels were significantly higher as compared with serum determination due to the matrix effect of each biological material, Glinicki et al. (2015), who used the CisBio IRMA, also found a good correlation between the 2 sample types $(r=0.8493 ; P<0.01)$. More importantly, each assay is performed by using different antibodies, with varying sensitivity and specificity. As a consequence, different kits may lead to significantly different results, hampering the possibility of pooling and/or comparing data obtained by different research centers with different assays (Gut et al. 2016). Indeed, results from antibodydependent assays are strikingly influenced by the employed antibodies. It has been reported that three different ELISA assays display different specificities for full-length CgA and its fragments, due to the use of the same capture antibody against CgA or VST I N-terminal regions coupled with three different detection antibodies against epitopes located in the central region of $\mathrm{CgA}$, or against the six C-terminal residues of full-length CgA, or the six C-terminal residues of VST I. Indeed, these assays could detect intact and processed $\mathrm{CgA}$, only intact $\mathrm{CgA}$ or only VST I, respectively (Helle \& Corti 2015). Therefore, the detection of intact/cleaved $\mathrm{CgA}$ depends on the employed antibody. Sensitivity and specificity of available methods have been compared by a number of studies. Stridsberg et al. (2003) came to the conclusion that the best compromise between sensitivity and specificity is the use of RIA. On the other hand, a prospective multicenter study demonstrated that ELISA and IRMA methods display a good diagnostic performance, providing results that are comparable and showing a satisfactory correlation $(r=0.843, P<0.0001)$ (Leon et al. 2005). Nevertheless, authors also reported a $36 \%$ discordance rate between the two methods, confirming previous findings (Ferrari et al. 2004) and suggesting that they might provide partially different information. These results were further strengthened by a multicenter study comparing a twostep IRMA (IRMA; CGA-RIA CT, CisBio internationalShering, Gif-sur-Yvette, France) and an ELISA assay (DAKO Cytomation, Glostrup, Denmark). The employed IRMA assay was based on two monoclonal antibodies raised against CgA-unprocessed central domain (CgA 145-245), thus detecting total human $\mathrm{CgA}$. On the other hand, the employed ELISA assay measured more CgA fragments, since it was based on two polyclonal rabbit antibodies directed toward a 23-kDa C-terminal CgA fragment. Results from the two assays were found to correlate and a receiving-operator characteristic (ROC) analysis found a cut-off of $53 \mathrm{ng} / \mathrm{mL}$ for IRMA and $16 \mathrm{U} / \mathrm{L}$ for ELISA as discriminating between controls and patients with active gastroenteropancreatic NENs (sensitivity 71.3 and 84\%; specificity 71 and 85\%, respectively) (Zatelli et al. 2007). An emerging CgA assay is the TRACE (KRYPTOR), a sandwich immunofluorescent method using two mouse monoclonal antibodies, based on a non-radioactive energy transfer between a donor (europium cryptate) and an acceptor (XL665). This assay has been recently compared with a widely used ELISA kit, the DAKO (Wolf et al. 2014). Authors showed an excellent correlation between serum samples analyzed with the first-generation KRYPTOR and those measured with the ELISA in EDTA plasma $(r=0.99)$. The workflow of the KRYPTOR was reported to be much faster than the ELISA, but it seems to be more sensitive to the storage temperature of the samples. Furthermore, the KRYPTOR assay issues different CgA levels depending on the sample origin (higher when starting from serum as compared to plasma), suggesting a possible interference by other analytes. Despite these limitations, the sensitivity of the method is promising since Popovici et al. (2014) showed values of 100 and $94 \%$ in pheochromocytoma/ paraganglioma and GEP NENs, respectively. A more recent study compared the results of the KRYPTOR assay with those of a solid-phase ELISA assay (CisBio) in serum samples (Van der Knaap et al. 2015). Authors found that CgA levels measured with the KRYPTOR method were significantly higher as compared to those measured by the ELISA CisBio, independently of gender, use of proton pump inhibitors (PPIs), renal function, referral department and tumor location. However, storage at low temperature $\left(-20^{\circ} \mathrm{C}\right)$ confirmed to be crucial for the analyte recovery, also indicating a low stability of the assay with time, which leads to progressive decay in CGA concentrations. This issue has been addressed by developing a secondgeneration assay, which uses two monoclonal antibodies recognizing different CgA epitopes, with a reduced 


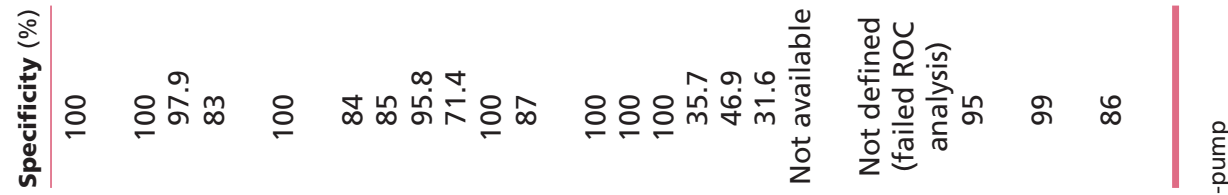

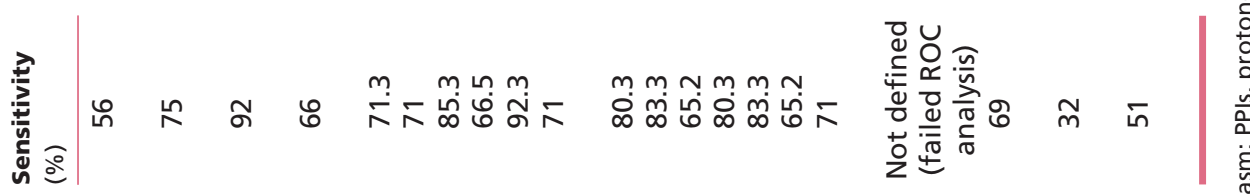

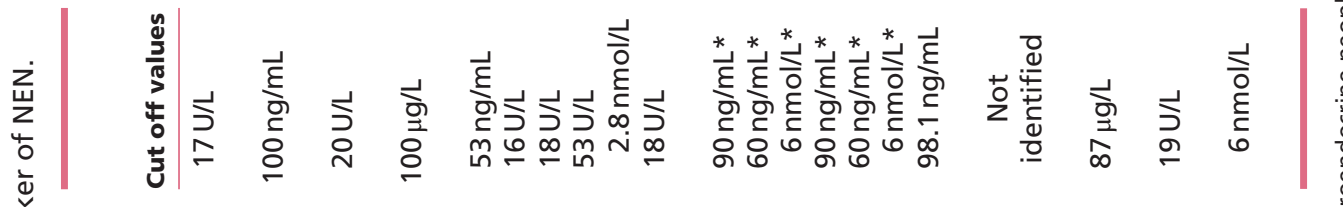
竞离|

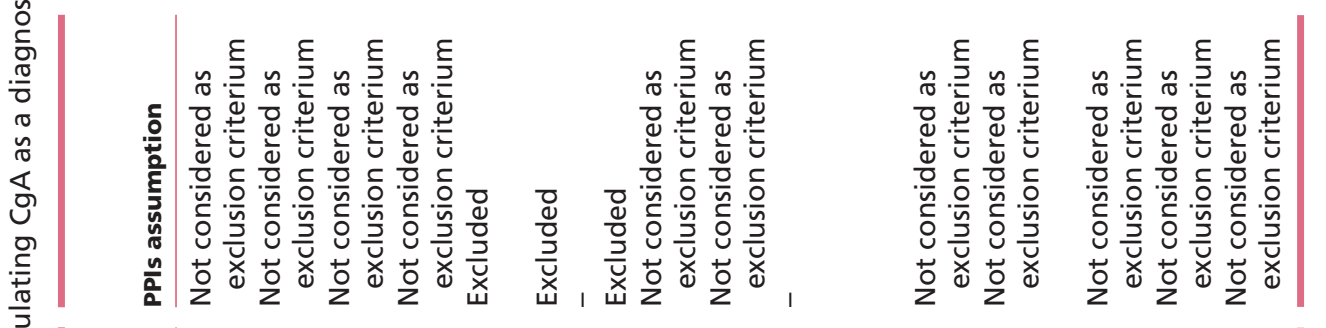

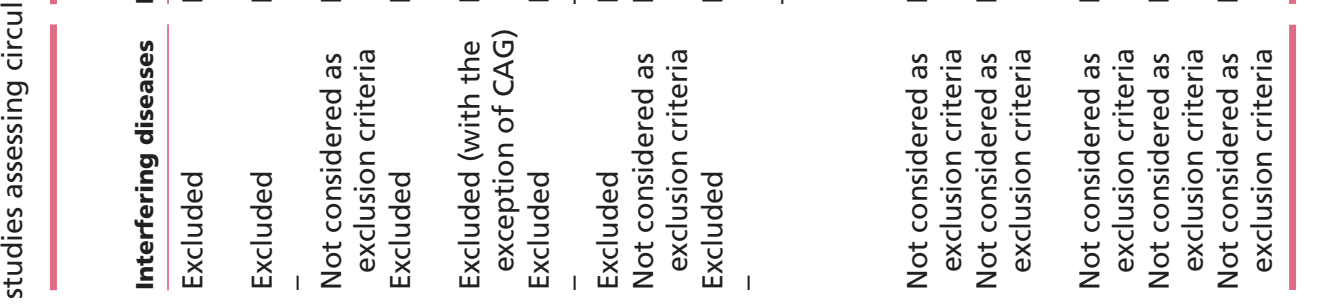

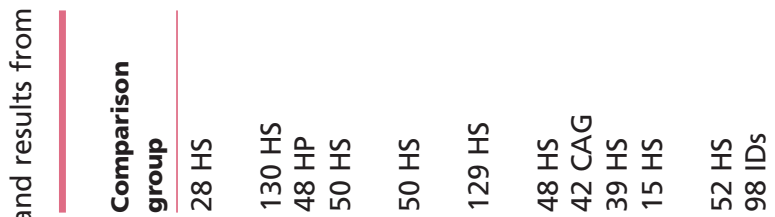

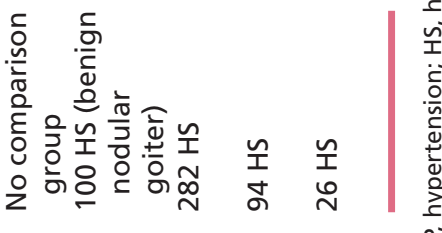

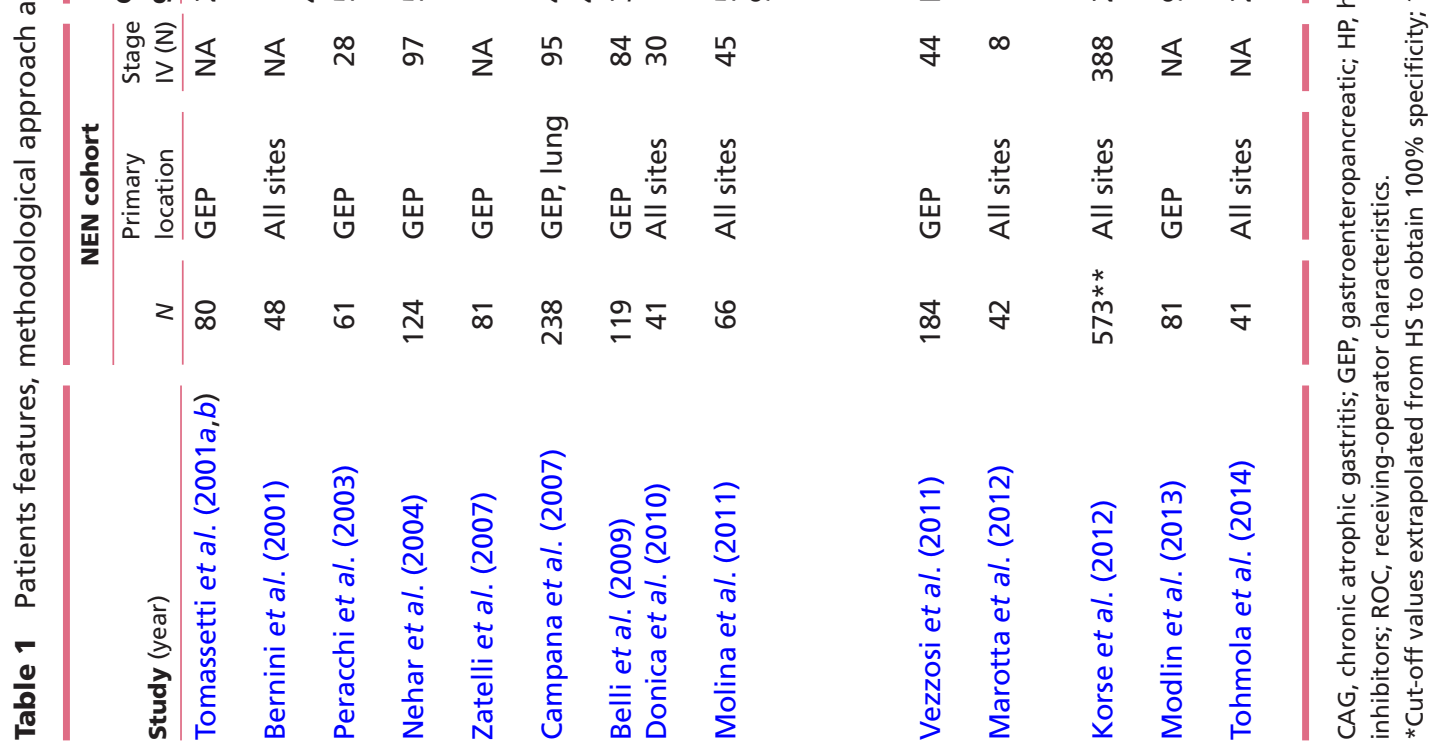


impact of protein folding on CgA measurement (Ferraro et al. 2016). Utility of this improved method has also been demonstrated in studies exploring the value of $\mathrm{CgA}$ as a predictive marker in tumors different from NENs (Niedworok et al. 2017). However, the application of this method in real-life clinical practice is still poor, so it does not impact in management of NENs at present.

\section{Circulating CgA in the diagnostic phase of NEN}

The definition of CgA metrics in NEN diagnostics is not univocal, as hampered by the wide variability of analytical approaches applied by the various studies.

The most critical discrepancies were (a) the composition of the case groups, with the strongest difference being represented by the fact that some studies included NEN from all sites (Bernini et al. 2001, Donica et al. 2010, Molina et al. 2011, Korse et al. 2012, Marotta et al. 2012, Tohmola et al.2014), whereas some others tried to analyze more homogeneous set of patients, mainly selecting gastroenteropancreatic tumors (Tomassetti et al. 2001a, Peracchi et al. 2003, Nehar et al. 2004, Zatelli et al . 2007, Belli et al. 2009, Modlin et al. 2013) (Table 1); (b) the composition of the control groups: although the majority of studies used healthy subjects as controls (Bernini et al. 2001, Tomassetti et al. 2001b, Peracchi et al. 2003, Nehar et al. 2004, Campana et al. 2007, Zatelli et al. 2007, Belli et al. 2009, Donica et al. 2010, Molina et al. 2011, Korse et al. 2012), which represents the best approach to assess the diagnostic performance of a marker (Shapiro 1999), some researchers determined the metrics of circulating CgA by comparing NEN with non-NEN tumors (Nobels et al. 1998, Panzuto et al. 2004) or active versus diseasefree NEN (Bajetta et al. 1999, Panzuto et al. 2004); (c) the consideration of interfering factors: some authors tried to clean up the control group from those conditions with known effect on CgA levels, thus obtaining a more pristine evaluation of marker specificity (Bernini et al. 2001, Tomassetti et al. 2001b, Nehar et al. 2004, Campana et al. 2007, Zatelli et al. 2007, Belli et al. 2009, Molina et al. 2011), whereas some others did not, thus providing data actually applicable into real-life practice (Peracchi et al. 2003, Donica et al. 2010, Korse et al. 2012, Marotta et al. 2012, Modlin et al. 2013, Tohmola et al. 2014) (Table 1).

\section{Specificity}

A wide range of conditions, both benign and malignant (Table 2), can induce NEN-unrelated CgA elevations, thus generating false-positive results (Ardill \& O'Dorisio 2010). This strikingly hampers test specificity, which is considered as the major weakness of circulating CgA in the diagnostic setting of NEN (Kidd et al. 2016, Modlin et al. 2010a).

\section{Non-oncological causes of CgA elevation}

Real-life application of circulating CgA for NEN diagnostics is hampered by a variety of interfering non-oncological conditions, including benign diseases and iatrogenic causes, which are extremely common. These conditions strikingly affect test specificity and should mandatorily be considered by clinicians when interpreting $\mathrm{CgA}$ values.

Since secretion of CgA is ubiquitary (Lamberts et al. 2001), a variety of non-neoplastic processes inducing tissue damage and remodeling may produce elevations of the marker. These include a variety of gastrointestinal disorders, such as chronic atrophic gastritis (CAG) (Peracchi et al. 2005), Helicobacter pylori infection (Waldum et al. 1996), liver cirrhosis and chronic hepatitis (Spadaro et al. 2005), pancreatitis (Malaguarnera et al. 2009), inflammatory bowel diseases (Sciola et al. 2009)

Table 2 Conditions affecting CgA-circulating levels.

\begin{tabular}{|c|c|c|}
\hline \multicolumn{2}{|l|}{ Non-oncological } & \multirow[b]{2}{*}{ Oncological } \\
\hline Benign diseases & latrogenic causes & \\
\hline $\begin{array}{l}\text { Gastrointestinal: chronic atrophic gastritis, Helicobacter pylori infection, } \\
\text { liver cirrosi, chronic hepatitis, pancreatitis, inflammatory bowel diseases, } \\
\text { irritable bowel }\end{array}$ & Proton pump inhibitors & Colorectal carcinoma \\
\hline Cardiovascular: hypertension, heart failure, acute coronary syndromes & $\begin{array}{l}\text { Histamine } 2 \text { receptor } \\
\text { antagonists }\end{array}$ & Gastric carcinoma \\
\hline Renal and hepatic dysfunctions & $\begin{array}{l}\text { Serotonin reuptake } \\
\text { inhibitors }\end{array}$ & Pancreatic carcinoma \\
\hline \multirow{2}{*}{$\begin{array}{l}\text { Others: giant cell arteritis, rheumatoid arthritis, systemic lupus } \\
\text { erythematosus, pulmonary obstructive disease, hyperthyroidism }\end{array}$} & & Prostate carcinoma \\
\hline & & $\begin{array}{l}\text { Breast carcinoma } \\
\text { Hepatocellular carcinoma } \\
\text { Ovarian carcinoma }\end{array}$ \\
\hline
\end{tabular}


and even irritable bowel syndrome (Sidhu et al. 2009). Among cardiovascular diseases, elevated CgA levels have been reported in hypertension, with higher levels being demonstrated in untreated patients (Takiyyuddin et al. 1995), chronic heart failure, where more accentuated elevations were detected in the fourth grade of the NHYA scale (Ceconi et al. 2002) and acute coronary syndromes, where higher concentrations predicted worsened outcome (Jansson et al. 2009). Other benign conditions increasing $\mathrm{CgA}$ levels include some rheumatoid diseases such as giant cell arteritis, rheumatoid arthritis and systemic lupus erythematosus (Di Comite et al. 2009a,b) and pulmonary obstructive disease (Hoshino et al. 2008). Due to reduced clearance, elevation of circulating CgA also occurs in the case of kidney and liver functional impairment (O'Connor et al. 1989). Particularly, the grade of renal dysfunction is directly related to CgA levels and may lead to concentrations as high as those detected in NEN patients (Hsiao et al. 1990). Ultimately, increased CgA levels have also been reported in endocrine disorders of non-neuroendocrine nature, such as hyperthyroidism, likely due to enhanced sympathetic activity which pairs with attenuation of the vagal tone (Al-Shoumer \& Vasanthy 2009). The main iatrogenic cause of CgA elevation is the use of PPIs and other acid-blocking drugs, which are largely administered by physicians (Fossmark et al. 2008). Indeed, inhibition of gastric acid production leads to compensative hypergastrinemia and G-cell hyperplasia, which in turn induce ECL-cell hyperplasia. Both G- and ECL-hyperplasia are responsible for CgA overproduction (Kuipers 2006). The role of the reported non-oncological conditions in affecting specificity of circulating $\mathrm{CgA}$ as a diagnostic marker of NEN emerges when comparing ROC analyses of studies trying to skim non-neoplastic controls for the presence of possible false-positive inductors with those not performing any selection (Table 1). Indeed, authors applying the former approach reported values ranging from 95 to 100\% (Bernini et al. 2001, Tomassetti et al. 2001b, Nehar et al. 2004, Campana et al. 2007, Belli et al. 2009, Molina et al. 2011), with the only exception of Zatelli et al. (2007), who found $84 / 85 \%$ specificity (based on the detection method) likely due to the fact that CAG was not ruled out. By contrast, specificity was less than $90 \%$ in the majority of studies where exclusion of interfering conditions was not performed (Peracchi et al. 2003, Donica et al. 2010, Vezzosi et al. 2011, Marotta et al. 2012, Tohmola et al. 2014). Furthermore, some authors specifically assessed the effect of benign conditions on test specificity by comparing the same cohort of NENs with separate groups of healthy subjects and patients carrying one or more interfering diseases (Table 1). Campana et al. (2007) selected a separate cohort of CAG patients reporting a drop, from 95.8 to $61.4 \%$, of $\mathrm{CgA}$ specificity. More recently, Molina et al. (2011) analyzed a separate group of patients with renal failure, gastric diseases, heart failure, liver cirrhosis, hypertension and inflammatory bowel diseases, showing a reduction in test specificity, which dropped from $100 \%$ to less than $50 \%$.

\section{Oncological causes of $\mathrm{CgA}$ elevation}

The actual impact of CgA elevation related to tumors other than NEN on test specificity is not univocal, due to the heterogeneity of available studies. However, the aim of future research should be to define performance of circulating $\mathrm{CgA}$ in differentiating NENs from those non-neuroendocrine malignancies posing an issue of differential diagnosis.

A variety of non-NEN malignancies are characterized by increased CgA levels (Glinicki \& Jeske 2011). The majority of them present a histological pattern of neuroendocrine differentiation, including several digestive tumors, such as colorectal adenocarcinoma (Syversen et al. 1995), gastric and pancreatic cancer (Malaguarnera et al. 2009) and prostate adenocarcinoma (Angelsen et al. 1997). By contrast, there are some tumors showing CgA elevation where the presence of histological neuroendocrine differentiation has not been reported, such as primary hepatocellular cancer (Spadaro et al. 2005) and breast cancer (Giovanella et al. 2001). To date, the capability of circulating CgA in discriminating NEN from other malignancies has been evaluated by many studies, which reported controversial results characterized by wide variation of specificity values (Nobels et al. 1998, Nehar et al. 2004, Panzuto et al. 2004, Molina et al. 2011, Marotta et al. 2012) (Table 3). This was likely due to the heterogeneity of both NEN groups and neoplastic controls, with the latter including different tumor types. However, the mentioned papers do not provide a real picture of clinical practice, where what is actually required is to distinguish NENs from non-neuroendocrine malignancies posing to clinicians issues of differential diagnosis. This is particularly crucial for non-functional NENs, given the absence of the distinctive clinical and biochemical features related to hormone overproduction (Kulke et al. 2015). To date, poor data are available about this issue. Some authors focused on the possible role of circulating $\mathrm{CgA}$ in determining differential diagnosis between the pancreatic NEN and the various pancreatic malignancies, such as ductal adenocarcinoma, cystic tumors, solid pseudopapillary tumors, acinar cell carcinoma, squamous 
Table 3 Composition of the study groups and results from studies assessing circulating $\mathrm{CgA}$ as a diagnostic marker between NEN and non-NEN tumors.

\begin{tabular}{|c|c|c|c|c|}
\hline Study (year) & NEN group & Non-NEN group & Sensitivity (\%) & Specificity (\%) \\
\hline Nobels et al. (1997) & 211 from all sites & $\begin{array}{l}\text { 180: breast carcinoma, non-small cell lung cancer, } \\
\text { pancreatic carcinoma, adenocarcinoma of } \\
\text { unknown origin, non-Hodgkin lymphoma, } \\
\text { Hodgkin lymphoma, multiple myeloma, } \\
\text { meningioma, and astrocytoma }\end{array}$ & 53 & 93 \\
\hline Panzuto et al. (2004) & 68 GEP & 24: gastric, colorectal, and pancreatic carcinoma & 84 & 63 \\
\hline Nehar et al. (2004) & 124 GEP & $\begin{array}{l}\text { 77: thyroid carcinoma, non-endocrine pancreatic } \\
\text { tumors, others unspecified }\end{array}$ & 62.9 & 97.4 \\
\hline Molina et al. (2011) & 66 from all sites & $\begin{array}{l}\text { 94: non-small cell lung cancer, colorectal } \\
\text { carcinoma, gastric carcinoma, pancreatic } \\
\text { carcinoma, prostatic carcinoma, hepatocellular } \\
\text { carcinoma, ovarian carcinoma, breast carcinoma } \\
\text { endometrial carcinoma, astrocytoma, } \\
\text { melanomas, sarcoma, and bladder carcinoma }\end{array}$ & 83.3 & 41.5 \\
\hline Marotta et al. (2012) & 42 from all sites & $\begin{array}{l}\text { 120: prostate carcinoma, colorectal carcinoma, } \\
\text { lung cancer (unspecified histology), hepatocel- } \\
\text { lular carcinoma, gastric carcinoma, papillary } \\
\text { thyroid carcinoma }\end{array}$ & $\begin{array}{l}\text { Not defined } \\
\text { (failed ROC } \\
\text { analysis) }\end{array}$ & $\begin{array}{l}\text { Not defined } \\
\text { (failed ROC } \\
\text { analysis) }\end{array}$ \\
\hline
\end{tabular}

GEP, gastroenteropancreatic; NEN, neuroendocrine neoplasm; ROC, receiving-operator characteristics.

cell carcinoma, lymphoma and metastatic lesions (Mulkeen et al. 2006). This is a challenging clinical issue as, despite the high specificity demonstrated by CT and MRI (Ichikawa et al. 2000, Sundin et al. 2009), the radiological phenotype of pancreatic NENs is variable, thus hampering instrumental diagnosis (Singhi et al. 2012). The retrospective analysis by Paik et al. (2013) reported only $56 \%$ specificity of the marker in differentiating pancreatic NENs from other pancreatic masses, whereas the prospective study by Jun et al. (2017), who specifically focused on patients suspected for a pancreatic NEN, showed a higher value, namely $77.8 \%$, which even rose to $100 \%$ when selecting lesions larger than $4 \mathrm{~cm}$. However, these data are not conclusive and the role of circulating CgA for the pre-surgical diagnosis of pancreatic NENs needs to be addressed in other clinical series.

\section{Sensitivity}

Sensitivity of circulating CgA can be considered as acceptable for functional and advanced NENs and extremely poor for localized non-functional disease. Since diagnosis of the latter is the most challenging for clinicians, this strongly limits the clinical utility of the test.

According to available studies (Table 1), sensitivity of circulating CgA for the diagnosis of NENs varies from 60 to 100\% (Oberg 2011). This represents a significant range of variation, which does not allow to define test sensitivity as acceptable or not. Actually, this is due to the fact that CgA levels are tightly related to disease-related features. Particularly, the main factors affecting the rate of abnormal $\mathrm{CgA}$, which determines the sensitivity of the test, are tumor function and disease extent. Regarding the former, Janson et al. (1997) first reported a high rate of CgA elevation, namely $86.1 \%$, in a large cohort of functional NENs from different sites. More recently, Nehar et al. (2004), focusing on a population of gastroenteropencreatic NENs, found CgA alterations in 70\% of secreting tumors, whereas only $40 \%$ of the non-functional ones showed positivity for the CgA test. Regarding the role of disease extent, the Nehar study (Nehar et al. 2004) also found a significant difference in the rate of CgA elevation between metastatic and non-metastatic patients, namely 73 vs 26\%. This dramatic impact on CgA sensitivity was further confirmed by Nikou et al. (2008), analyzing a cohort of non-functional pancreatic NEN, who found CgA alterations in the totality of patients with liver metastases, whereas the rate was much lower, $66.6 \%$, in those subjects without liver involvement. According to these data, sensitivity of the CgA test can be considered as acceptable only for functional and advanced NENs. Recently, Jilesen et al. (2014), analyzing a cohort of non-metastatic nonfunctional pancreatic NENs, found CgA elevation in only $27 \%$ of the cases, further demonstrating the poor marker sensitivity in early non-functional disease. This strikingly limits clinical utility of circulating $\mathrm{CgA}$ as diagnosis of functional and metastatic NENs is mainly obtained by specific biomarkers and imaging modalities or biopsy, respectively (Jensen et al. 2012, Pavel et al. 2012), 
whereas a stronger support from biochemistry would be specifically required for localized non-secreting NENs, where diagnosis is more challenging.

\section{Diagnostic role of circulating $\mathrm{CgA}$ in particular clinical settings}

\section{CAG and inflammatory bowel diseases}

CAG and inflammatory bowel diseases, already defined as non-oncological causes of $\mathrm{CgA}$ elevation, represent for clinicians a diagnostic challenge as they also predispose to NEN development through stimulating proliferation of neuroendocrine cells (Ruszniewski et al. 2006, West et al. 2007). The possible role of circulating CgA in discriminating patients with CAG and inflammatory bowel diseases who develop gastric (type I) and intestinal NEN, respectively, has been tested by few studies, with non-encouraging results. Peracchi et al. (2005) found higher CgA levels in CAG patients with gastric NEN, as compared with those without, but specificity of the test was extremely poor (23\%), whereas Sciola et al. (2009) reported non-significant differences in CgA levels between inflammatory bowel diseases with and without concomitant intestinal NEN.

\section{Multiple endocrine neoplasia type 1-related NENs}

MEN1 is an autosomal dominant hereditary syndrome predisposing to the development of a variety of NENs. The most common are pancreatic NENs, occurring in $40-70 \%$ of the patients, whereas gastric, bronchial and thymic tumors are less frequent (Thakker et al. 2012). Importantly, NENs represent the main cause of MEN1related death (Goudet et al. 2010). Therefore, a proper screening approach is required in order to detect NENs as early as possible, thus obtaining a reduction in MEN1related morbidity and mortality (Pieterman et al. 2009, Ramundo et al. 2011). To date, the standard of care suggests annual CgA determination, but this statement is defined as 'low quality' (Thakker et al. 2012). Indeed, the actual value of circulating CgA as a screening test for NEN diagnosis in patients with MEN1 is still controversial as it has been assessed by very few studies. In 2003, Peracchi et al. (2003) found CgA alterations in the vast majority, 15 out of 16 cases, of MEN1 patients affected with gastroenteropancreatic NENs, and this was consistent with a possible use of $\mathrm{CgA}$ as the screening test. Nevertheless, 2 recent publications (de Laat et al. 2013, Qiu et al. 2016), analyzing larger cohorts of MEN1 subjects and specifically focusing on the detection of pancreatic NENs, provided opposite results. Indeed, both research groups consistently demonstrated low diagnostic accuracy for $\mathrm{CgA}$, also reporting poor sensitivity values, which is not feasible to use the marker as the screening test.

\section{Circulating CgA as a prognostic marker in NEN}

There is prospective evidence which demonstrates that advanced NENs secreting CgA have poorer outcome, as compared with those showing non-elevated marker levels. By contrast, data about localized disease are still poor.

Circulating CgA has long been used as an indirect survival predictor in clinical practice of NEN management. This was due to the well-demonstrated relationship with disease stage/extent, which represents the main predictor of clinical outcome (Ahmed et al. 2009). Indeed, the majority of authors demonstrated higher marker levels in patients with extensive metastases, as compared with those having localized disease or even limited hepatic involvement (Janson et al. 1997, Tomassetti et al. 2001b, Nehar et al. 2004, Campana et al. 2007, Zatelli et al. 2007, Nikou et al. 2008). Furthermore, Arnold et al. (2008) reported a direct correlation between the CgA increase and the extent of liver involvement. Nevertheless, such correlation is not valid for all NEN types as CgA levels may be affected by many other clinico-pathological features. As an example, due to direct tumor secretion and gastrin-induced ECL-cell hyperplasia, non-metastatic gastrinomas show CgA levels as high as those reported in metastatic non-functional pancreatic NENs (Janson et al. 1997), so the association with disease load and the indirect prognostic significance are lost in this case. Hence, the actual prognostic impact of circulating CgA can be assessed only analyzing the direct relationship with survival. This has been performed in a wide variety of retrospective analyses, all demonstrating that high $\mathrm{CgA}$ levels were predictors of poor survival (Janson et al. 1997, Arnold et al. 2008, Ekeblad et al. 2008, Nikou et al. 2008, Citterio et al. 2017, Nanno et al. 2017). Of note, the majority of these studies were focused on advanced disease, which has to be considered as the most important setting, since a proper prognostic stratification of these patients is mandatory. Arnold et al. (2008) showed that plasma CgA levels were related to survival time in a cohort of 344 patients with metastatic, well-differentiated NENs of gastroenteropancreatic origin. More recently, Citterio et al. (2017) evaluated a more homogeneous set of patients including 139 well-differentiated NENs with metastatic liver involvement. Authors identified basal CgA levels less than $200 \mathrm{ng} / \mathrm{mL}$ as a positive prognostic factor, and this 
result was confirmed after a multivariate analysis. To date, prospective evidence about this issue has been provided by the RADIANT-1, -2 and -3 trials, where dedicated analyses were performed in order to assess a prognostic value of circulating CgA in the whole cohort of advanced NENs, independently of the prediction of treatment efficacy (Yao et al. 2008b, 2010, 2016, Pavel et al. 2017b). These studies considered patients showing circulating levels higher than 2-fold the upper normal limit as CgA secretors, while subjects with marker levels equal or below this cut-off were classified as having non-elevated CgA. In all cases, authors demonstrated shorter overall survival (OS) for patients with advanced NENs showing elevated $\mathrm{CgA}$, who represented from 50 to $70 \%$ of the study cohorts. To date, data about localized disease are extremely poor. Recently, Nanno et al. (2017) analyzed a cohort of resectable, welldifferentiated pancreatic NENs finding that preoperative serum CgA levels were significantly higher in patients with postoperative recurrence, as compared to those without recurrence. However, these findings need further confirmation in independent series.

\section{Circulating CgA in the follow-up phase of NEN}

The follow-up phase of NENs essentially includes 2 clinical situations: (a) patients being cured after surgery (R0 resection), where the objective is to identify relapses; (b) subjects with more advanced tumor who do not or cannot achieve a disease-free status, where the objective is to monitor morphological evolution, in order to detect transition from stable to progressive disease (Modlin et al. $2010 b$ ). Since these patients can be subjected to a variety of treatments, which are usually administered sequentially or even simultaneously during the course of the disease, monitoring the tumor slope represents the mainstay for a proper clinical management. Here, we report current evidence about the value of circulating $\mathrm{CgA}$ in each of the described settings.

\section{Detection of tumor relapse after curative surgery}

Evidence of the role of circulating CgA in this setting is still poor as based on few and controversial studies.

Initially, a retrospective study of 56 patients was consistent with a possible value of $\mathrm{CgA}$ as a marker of disease recurrence in midgut NENs subjected to radical surgery. Authors showed that $\mathrm{CgA}$ rising above the normal range represented the first indicator of the recurrence, even anticipating 5-hydroxyindolylacetic acid positivization and instrumental examinations (Welin et al. 2009). Therefore, a twice-a-year CgA determination together with transabdominal ultrasonography was proposed as a feasible follow-up scheme. In contrast to these findings, a recent study providing prospective evaluation of 15 R0-resected gastroenteropancreatic NENs reported no CgA elevation in the 2 subjects developing recurrence who had elevated pre-surgical levels (Modlin et al. 2016). Despite the low number of cases, this was consistent with a poor utility of the marker in the follow-up of NENs after curative surgery.

\section{Assessment of morphological evolution in patients with} non-cured disease

Based on recently published prospective studies, the trend of circulating CgA over time cannot be considered as a valid marker of morphological evolution of NENs with persistent disease and its utility in the follow-up of these patients is therefore poor.

Initially, promising insights about the relationship between circulating $\mathrm{CgA}$ and morphological evolution of non-cured NENs were provided by 2 retrospective studies (Bajetta et al. 1999, Nehar et al. 2004). Both research groups found high concordance between CgA changes and tumor slope, demonstrating that marker elevation higher than 25\% was a highly sensitive predictor ( 83 and $89 \%$, respectively) of tumor progression. In contrast to these findings, a more recent retrospective study by Walter et al. (2012) found that marker changes were consistent with morphology in only $51 \%$ of the cases and that a significant CgA elevation, defined as an at least 50\% increase, was detectable in only $56 \%$ of the patients with progressive disease. More definite evidence about this issue has emerged in the last 2 years, with 2 prospective reports demonstrating the poor capability of $\mathrm{CgA}$ changes in reflecting morphological behavior of NENs. In 2015, Cwikla et al. (2015) prospectively analyzed a cohort of 28 non-cured gastroenteropancreatic NENs treated with somatostatin analogues (SSA). Considering an at least $25 \%$ increase as cut-off, authors found low concordance, namely $64 \%$, between CgA modifications and tumor slope. Particularly, only $57 \%$ of progressing patients showed significant CgA increase. Similarly, a 2017 study by Pavel et al. (2017a) of 34 advanced gastroenteropancreatic NENs subjected to various treatments, which also considered $25 \%$ increase as cut-off, reported only $40 \%$ concordance between morphological behavior and CgA modifications. 


\section{Circulating CgA for the definition of treatment strategy}

Currently, a variety of tools are available for NEN treatment. Besides surgery, radical or debulking, these include several medical therapies (SSA, interferon alfa, targeted agents such as tyrosine kinase and mTOR inhibitors, and chemotherapy), PRRT and loco-regional treatments (radiofrequency ablation and transarterial embolization) (Modlin et al. 2010b, Oberg et al. 2010, Frilling et al. 2012, Pavel et al. 2012, Marotta et al. 2013, Del Prete et al. 2014, Fiore et al. 2014, Ramundo et al. 2014). This poses 2 major challenges for clinicians, who are required (a) to choose the best therapy for each specific patient; (b) to test as early as possible effectiveness of the chosen approach in order to perform a prompt adjustment of treatment strategy. Here, we analyze current role of circulating $\mathrm{CgA}$ in this context.

\section{Baseline $\mathrm{CgA}$ as predictive marker of treatment efficacy}

The best available evidence, deriving from two prospective placebo-controlled studies, shows no role of baseline CgA as a predictive marker of response to treatment.

Actually, promising insights about this issue were initially provided from a dedicated analysis extrapolated from the phase II RADIANT-1 study of everolimus in advanced pancreatic NETs (Yao et al. 2011a). Indeed, authors demonstrated that CgA levels $>2$ fold the upper normal limit were associated with significant reduction in both PFS and OS. However, the absence of a placebo group strongly limited the validity of the reported relationship, which could be simply due to the prognostic effect of $\mathrm{CgA}$ rather than to an actual interaction with the treatment. This thesis was subsequently confirmed by RADIANT- 2 and -3 , which were randomized, placebocontrolled trials of everolimus in advanced NENs with carcinoid syndrome under SSA treatment and advanced pancreatic NENs, respectively (Pavel et al. 2011, Yao et al. $2011 b$ ). Indeed, recent post hoc analyses of both studies specifically assessed whether baseline CgA levels were only prognostic or had actual capability of predicting treatment effect on OS (Yao et al. 2016, 2017, Pavel et al. $2017 b$ ). This was done by adjusting OS of the 2 study arms for pre-treatment CgA levels, which were imbalanced. Authors concluded that baseline $\mathrm{CgA}$ was not predictive of everolimus impact on outcome. Recently, the lack of predictive value of pre-treatment marker levels was also suggested for NENs subjected to PRRT, an established therapeutic modality mainly used for inoperable or metastatic gastroenteropancreatic NENs (van der Zwan et al. 2015). Even if limited by the lack of a control group of untreated subjects, a recent prospective study by Bodei et al. (2016) showed no impact of elevated CgA $(>600 \mathrm{ng} / \mathrm{mL}$ ) on both morphological response and PFS.

$\mathrm{CgA}$ response as a predictive marker of treatment efficacy

Subanalyses from 2 prospective placebo-controlled studies reported CgA response as a predictor of medical treatment efficacy. Regarding surgery and PRRT, the best prospective evidence, based on single dedicated studies, shows no value of $\mathrm{CgA}$ changes as a predictive marker of response.

The mentioned analysis from the RADIANT-1 reported that, among patients with elevated baseline levels, an early $\mathrm{CgA}$ response, defined as an at least $30 \%$ reduction of the marker at 4 weeks treatment, was predictive of morphological response, PFS, and OS (Yao et al. 2011a). This was consistent with the previous retrospective observation that an early $\mathrm{CgA}$ decrease was associated with improved RECIST response and clinical outcome in pancreatic NENs subjected to streptozocinbased chemotherapy (Kouvaraki et al. 2004). As previously discussed, these findings were intrinsically limited by the absence of a control group. However, the role of $\mathrm{CgA}$ reduction as a predictive marker of response to medical therapies has found some confirmation through dedicated subanalyses of placebo-controlled trials. In 2011, a contribution to the European Society for Medical Oncology Congress, based on data from the RADIANT-2 trial, confirmed that early CgA responders had longer PFS, as compared with non-responders (Baudin et al. 2011). More recently, a subanalysis of the CLARINET study, a randomized phase III trial of lanreotide in advanced NENs, showed that a decrease in CgA was associated with reduced hazard of disease progression (Buil-Bruna et al. 2016). Regarding surgery and PRRT, the mentioned Modlin study (Modlin et al. 2016), providing prospective evaluation of gastroenteropancreatic NENs treated with surgery, found no significant postsurgical CgA changes between cured and non-cured patients. Similarly, the prospective Bodei study (Bodei et al. 2016) about PRRT found that the rate of $\mathrm{CgA}$ reduction was higher in non-responders than in responding cases (21 and $40 \%$, respectively), thus indicating poor utility of $\mathrm{CgA}$ modifications in predicting treatment efficacy. 


\section{Conclusions}

A wide body of research has been dedicated over the last 2 decades to define clinical application of circulating CgA in NENs. As all authors agree, the marker is intrinsically limited by the lack of assay standardization generating significant variations across different laboratories. This depends not only on the applied technique, but also on the employed antibody when using the same method (Modlin et al. 2010a), and hampers not only management of a single patient, but also the comparison between different studies, thus making hard to define the actual marker performance. Clinical value of $\mathrm{CgA}$ in the diagnostic setting is hampered by issues impairing both specificity and sensitivity. Regarding the former, the major problem is that several conditions other than NEN can affect CgA levels, therefore acting as confounding factors. These include some highly prevalent non-oncological conditions, such as gastrointestinal and cardiovascular disorders or PPIs assumption, and a variety of non-NEN tumors. Among the latter, those with the highest impact in clinical practice are malignancies arising from anatomic areas where NENs occur more frequently, such as colorectal and pancreatic adenocarcinoma. Sensitivity of the test is intrinsically limited by the fact that a relevant portion of NENs, 30-50\%, do not show elevated CgA levels (Lindholm \& Oberg 2011). Due to the tight correlation of the marker with tumor function and disease extent, this issue mainly involves NENs with non-functionally localized disease where CgA is normal in about $70 \%$ of the cases (Jilesen et al. 2014). In this kind of patients, where the role of clinics and instrumental exams is limited and the need of an accurate biochemical marker is higher, a diagnostic role of circulating $\mathrm{CgA}$ is paradoxically marginal, due to the poor sensitivity. The insufficient diagnostic utility of CgA has been recently formalized in a Delphi consensus, stating that no single circulating biomarker meets the minimum required standard, namely sensitivity and specificity higher than 80 and $90 \%$, respectively, to be considered as a supportable diagnostic tool (Oberg et al. 2015). This contrasts with current indications from the ENETS and the other major societies dealing with NENs, which still recommend broad spectrum use of circulating CgA for the diagnostic definition (Kloppel et al. 2009, O'Toole et al. 2009, Jensen et al. 2012, Oberg et al. 2012a,b, Ramage et al. 2012, Kunz et al. 2013, Caplin et al. 2015, Kulke et al. 2015, Falconi et al. 2016, Niederle et al. 2016). It is our opinion that societal guidelines should be updated better addressing the actual diagnostic value of circulating $\mathrm{CgA}$, thus avoiding incorrect and expensive use of the marker.

Regarding the prognostic value of $\mathrm{CgA}$, there is prospective evidence that advanced NENs with elevated CgA have poor outcome. Owing to the wide variability in disease evolution of stage IV NENs (Baudin 2007, Baudin et al. 2012), which makes essential to perform prognostic stratification of these patients, this can be considered as the most important clinical application of circulating CgA. However, elevated $\mathrm{CgA}$ is detectable in a wide proportion, namely $50-70 \%$, of advanced NENs, so the identification of cut-offs allowing a proper risk stratification among patients secreting the protein is required.

Regarding the follow-up phase, recent prospective studies (Cwikla et al. 2015, Pavel et al. 2017a) show that circulating $\mathrm{CgA}$ does not represent a valid marker of morphological evolution of disease and has therefore no utility in this setting.

Regarding the role of $\mathrm{CgA}$ for the definition of treatment strategy, available evidence is overall poor as limited by the small number of dedicated studies and, also, by the retrospective nature as well as the absence of control groups of untreated subjects characterizing the majority of them. Nevertheless, dedicated analyses from the most recent prospective placebo-controlled trials (Yao et al. 2016, 2017, Pavel et al. 2017b) demonstrated no CgA role for predicting the impact of a medical treatment on survival. However, it is important to remark that $\mathrm{CgA}$, per definition, can be used as a marker only in NENs showing abnormal serum level. Since the portion of NENs with normal CgA is remarkable, accounting for $30-50 \%$ of the patients, this strongly limits the actual clinical application of the marker.

In conclusion, despite representing the best available monoanalyte marker related to NEN (Modlin et al. 2010b, Kulke et al. 2015), CgA carries the typical limitations of single-analyte measurements (Hood \& Tian 2012), and is therefore unable to provide comprehensive evaluation of a heterogeneous entity such as NEN (Baudin 2007, Yao et al. 2008a). Hence, the new frontier seems to be represented by multianalyte approaches. Particularly, a blood-based algorithm including simultaneous determination of 51 NEN-specific markers has been developed in recent years (Modlin et al. 2013), and all comparative studies were concordant in reporting significantly better metrics, as compared with CgA (Modlin et al. 2014a,b, 2015, 2016, Bodei et al. 2016, Pavel et al. 2017a). 


\section{Declaration of interest}

The authors declare that there is no conflict of interest that could be perceived as prejudicing the impartiality of this review.

\section{Funding}

This work was supported by the Umberto Veronesi Foundation, which granted the lead author Vincenzo Marotta with a postdoctoral Fellowship award for 2017.

\section{Acknowledgements}

The authors acknowledge the Umberto Veronesi Foundation for the postdoctoral Fellowship award 2017 provided to Vincenzo Marotta.

\section{References}

Aardal S, Helle KB, Elsayed S, Reed RK \& Serck-Hanssen G 1993 Vasostatins, comprising the N-terminal domain of chromogranin A, suppress tension in isolated human blood vessel segments. Journal of Neuroendocrinology 5 405-412. (https://doi. org/10.1111/j.1365-2826.1993.tb00501.x)

Ahmed A, Turner G, King B, Jones L, Culliford D, McCance D, Ardill J, Johnston BT, Poston G, Rees M, et al. 2009 Midgut neuroendocrine tumours with liver metastases: results of the UKINETS study. Endocrine-Related Cancer 16 885-894. (https://doi.org/10.1677/ERC09-0042)

Al-Shoumer KA \& Vasanthy BA 2009 Serum chromogranin A concentration in hyperthyroidism before and after medical treatment. Journal of Clinical Endocrinology and Metabolism 94 2321-2324. (https://doi.org/10.1210/jc.2008-2231)

Angelsen A, Syversen U, Haugen OA, Stridsberg M, Mjolnerod OK \& Waldum HL 1997 Neuroendocrine differentiation in carcinomas of the prostate: do neuroendocrine serum markers reflect immunohistochemical findings? Prostate 30 1-6. (https://doi. org/10.1002/ (SICI)1097-0045(19970101)30:1<1::AID-PROS1>3.0.CO;2-T)

Ardill JE \& O’Dorisio TM 2010 Circulating biomarkers in neuroendocrine tumors of the enteropancreatic tract: application to diagnosis, monitoring disease, and as prognostic indicators. Endocrinology Metabolism Clinics of North America 39 777-790. (https://doi.org/10.1016/j.ecl.2010.09.001)

Arnold R, Wilke A, Rinke A, Mayer C, Kann PH, Klose KJ, Scherag A, Hahmann M, Muller HH \& Barth P 2008 Plasma chromogranin A as marker for survival in patients with metastatic endocrine gastroenteropancreatic tumors. Clinical Gastroenterology and Hepatology 6 820-827. (https://doi.org/10.1016/j.cgh.2008.02.052)

Arvan P, Kuliawat R, Prabakaran D, Zavacki AM, Elahi D, Wang S \& Pilkey D 1991 Protein discharge from immature secretory granules displays both regulated and constitutive characteristics. Journal of Biological Chemistry 266 14171-14174.

Bajetta E, Ferrari L, Martinetti A, Celio L, Procopio G, Artale S, Zilembo N, Di Bartolomeo M, Seregni E \& Bombardieri E 1999 Chromogranin A, neuron specific enolase, carcinoembryonic antigen, and hydroxyindole acetic acid evaluation in patients with neuroendocrine tumors. Cancer 86 858-865. (https://doi org/10.1002/(SICI)1097-0142(19990901)86:5<858::AIDCNCR23>3.0.CO;2-8)

Baudin E 2007 Gastroenteropancreatic endocrine tumors: clinical characterization before therapy. Nature Clinical Practice Endocrinology and Metabolism 3 228-239. (https://doi.org/10.1038/ ncpendmet0425)
Baudin E, Wolin E, Castellano D, Kaltsas G, Panneerselvam A, Tsuchihashi Z, Saletan S, Yao JC \& Gross D 20116564 POSTER Correlation of PFS with early response of chromogranin A and 5-hydroxyindoleacetic acid levels in Pts with advanced neuroendocrine tumours: phase III RADIANT-2 study results. European Journal of Cancer 74 (Supplement 1) S460. (https://doi. org/10.1016/S0959-8049(11)71875-5)

Baudin E, Planchard D, Scoazec JY, Guigay J, Dromain C, Hadoux J, Debaere T, Elias D \& Ducreux M 2012 Intervention in gastroenteropancreatic neuroendocrine tumours. Best Practice and Research: Clinical Gastroenterology 26 855-865. (https://doi.org/10.1016/j. bpg.2013.01.008)

Belli SH, Oneto A, Aranda C, O'Connor JM, Domenichini E, Roca E, Mendez G, Bestani MC, Parma P, Giacomi N, et al. 2009 Chromogranin A as a biochemical marker for the management of neuroendocrine tumors: a multicenter study developed in Argentina. Acta Gastroenterologica Latinoamericana 39 184-189.

Belloni D, Scabini S, Foglieni C, Veschini L, Giazzon A, Colombo B, Fulgenzi A, Helle KB, Ferrero ME, Corti A, et al. 2007 The vasostatin-I fragment of chromogranin A inhibits VEGF-induced endothelial cell proliferation and migration. FASEB Journal 21 3052-3062. (https://doi.org/10.1096/fj.06-6829com)

Bernini GP, Moretti A, Ferdeghini M, Ricci S, Letizia C, D'Erasmo E, Argenio GF \& Salvetti A 2001 A new human chromogranin 'A' immunoradiometric assay for the diagnosis of neuroendocrine tumours. British Journal of Cancer 84 636-642. (https://doi. org/10.1054/bjoc.2000.1659)

Blind E, Schmidt-Gayk H, Sinn HP, O'Connor DT \& Raue F 1992 Chromogranin A as tumor marker in medullary thyroid carcinoma. Thyroid 2 5-10. (https://doi.org/10.1089/thy.1992.2.5)

Blois A, Srebro B, Mandala M, Corti A, Helle KB \& Serck-Hanssen G 2006 The chromogranin A peptide vasostatin-I inhibits gap formation and signal transduction mediated by inflammatory agents in cultured bovine pulmonary and coronary arterial endothelial cells. Regulatory Peptides 135 78-84. (https://doi.org/10.1016/j. regpep.2006.04.007)

Bodei L, Kidd M, Modlin IM, Severi S, Drozdov I, Nicolini S, Kwekkeboom DJ, Krenning EP, Baum RP \& Paganelli G 2016 Measurement of circulating transcripts and gene cluster analysis predicts and defines therapeutic efficacy of peptide receptor radionuclide therapy (PRRT) in neuroendocrine tumors. European Journal of Nuclear Medicine and Molecular Imaging 43 839-851. (https://doi.org/10.1007/s00259-015-3250-z)

Borges R, Diaz-Vera J, Dominguez N, Arnau MR \& Machado JD 2010 Chromogranins as regulators of exocytosis. Journal of Neurochemistry 114 335-343. (https://doi.org/10.1111/j.1471-4159.2010.06786.x)

Borges R, Dominguez N, Smith CB, Bandyopadhyay GK, O'Connor DT, Mahata SK \& Bartolomucci A 2013 Granins and catecholamines: functional interaction in chromaffin cells and adipose tissue. Advances in Pharmacology 68 93-113.

Buil-Bruna N, Dehez M, Manon A, Nguyen TX \& Troconiz IF 2016 Establishing the quantitative relationship between lanreotide Autogel(R), chromogranin A, and progression-free survival in patients with nonfunctioning gastroenteropancreatic neuroendocrine tumors. AAPS Journal 18 703-712. (https://doi.org/10.1208/s12248016-9884-3)

Campana D, Nori F, Piscitelli L, Morselli-Labate AM, Pezzilli R, Corinaldesi R \& Tomassetti P 2007 Chromogranin A: is it a useful marker of neuroendocrine tumors? Journal of Clinical Oncology 25 1967-1973. (https://doi.org/10.1200/JCO.2006.10.1535)

Caplin ME, Baudin E, Ferolla P, Filosso P, Garcia-Yuste M, Lim E, Oberg K, Pelosi G, Perren A, Rossi RE, et al. 2015 Pulmonary neuroendocrine (carcinoid) tumors: European Neuroendocrine Tumor Society expert consensus and recommendations for best practice for typical and atypical pulmonary carcinoids. Annals of Oncology 26 1604-1620. (https://doi.org/10.1093/annonc/mdv041) 
Ceconi C, Ferrari R, Bachetti T, Opasich C, Volterrani M, Colombo B, Parrinello G \& Corti A 2002 Chromogranin A in heart failure; a novel neurohumoral factor and a predictor for mortality. European Heart Journal 23 967-974. (https://doi.org/10.1053/euhj.2001.2977)

Citterio D, Pusceddu S, Facciorusso A, Coppa J, Milione M, Buzzoni R, Bongini M, deBraud F \& Mazzaferro V 2017 Primary tumour resection may improve survival in functional well-differentiated neuroendocrine tumours metastatic to the liver. European Journal of Surgical Oncology 43 380-387. (https://doi.org/10.1016/j. ejso.2016.10.031)

Cwikla JB, Bodei L, Kolasinska-Cwikla A, Sankowski A, Modlin IM \& Kidd M 2015 Circulating transcript analysis (NETest) in GEP-NETs treated with somatostatin analogs defines therapy. Journal of Clinical Endocrinology and Metabolism 100 E1437-E1445. (https://doi. org/10.1210/jc.2015-2792)

de Laat JM, Pieterman CR, Weijmans M, Hermus AR, Dekkers OM, de Herder WW, van der Horst-Schrivers AN, Drent ML, Bisschop PH, Havekes B, et al. 2013 Low accuracy of tumor markers for diagnosing pancreatic neuroendocrine tumors in multiple endocrine neoplasia type 1 patients. Journal of Clinical Endocrinology and Metabolism $\mathbf{9 8}$ 4143-4151. (https://doi.org/10.1210/jc.2013-1800)

Del Prete M, Fiore F, Modica R, Marotta V, Marciello F, Ramundo V, Di Sarno A, Carratu A, di Roseto Cde L, Tafuto S, et al. 2014 Hepatic arterial embolization in patients with neuroendocrine tumors. Journal of Experimental and Clinical Cancer Research 3343. (https://doi.org/10.1186/1756-9966-33-43)

Di Comite G, Previtali P, Rossi CM, Dell'Antonio G, Rovere-Querini P, Praderio L, Dagna L, Corti A, Doglioni C, Maseri A, et al. 2009a High blood levels of chromogranin A in giant cell arteritis identify patients refractory to corticosteroid treatment. Annals of the Rheumatic Diseases 68 293-295.

Di Comite G, Rossi CM, Marinosci A, Lolmede K, Baldissera E, Aiello P, Mueller RB, Herrmann M, Voll RE, Rovere-Querini P, et al. $2009 b$ Circulating chromogranin A reveals extra-articular involvement in patients with rheumatoid arthritis and curbs TNF-alpha-elicited endothelial activation. Journal of Leukocyte Biology 85 81-87.

Dimsdale JE, O'Connor DT, Ziegler M \& Mills P 1992 Chromogranin A correlates with norepinephrine release rate. Life Science 51 519-525. (https://doi.org/10.1016/0024-3205(92)90029-O)

Donica H, Malecha-Jedraszek A, Stroslawska E, Burska A \& Szubstarski F 2010 Significance of plasma chromogranin A determination in neuroendocrine tumour (NET) diagnosis. Folia Histochemica et Cytobiologica 48 603-610.

Ekeblad S, Skogseid B, Dunder K, Oberg K \& Eriksson B 2008 Prognostic factors and survival in 324 patients with pancreatic endocrine tumor treated at a single institution. Clinical Cancer Research 14 7798-7803. (https://doi.org/10.1158/1078-0432.CCR-08-0734)

Faggiano A, Ferolla P, Grimaldi F, Campana D, Manzoni M, Davi MV, Bianchi A, Valcavi R, Papini E, Giuffrida D, et al. 2012 Natural history of gastro-entero-pancreatic and thoracic neuroendocrine tumors. Data from a large prospective and retrospective Italian epidemiological study: the NET management study. Journal of Endocrinological Investigation 35 817-823.

Fairweather M, Swanson R, Wang J, Brais LK, Dutton T, Kulke MH \& Clancy TE 2017 Management of neuroendocrine tumor liver metastases: long-term outcomes and prognostic factors from a large prospective database. Annals of Surgical Oncology [epub]. (https://doi. org/10.1245/s10434-017-5839-x)

Falconi M, Eriksson B, Kaltsas G, Bartsch DK, Capdevila J, Caplin M, Kos-Kudla B, Kwekkeboom D, Rindi G, Kloppel G, et al. 2016 ENETS Consensus Guidelines update for the management of patients with functional pancreatic neuroendocrine tumors and non-functional pancreatic neuroendocrine tumors. Neuroendocrinology 103 153-171. (https://doi.org/10.1159/000443171)

Ferolla P, Faggiano A, Mansueto G, Avenia N, Cantelmi MG, Giovenali P, Del Basso De Caro ML, Milone F, Scarpelli G, Masone S, et al. 2008
The biological characterization of neuroendocrine tumors: the role of neuroendocrine markers. Journal of Endocrinological Investigation 31 277-286. (https://doi.org/10.1007/BF03345602)

Ferrari L, Seregni E, Lucignani G, Bajetta E, Martinetti A, Aliberti G, Pallotti F, Procopio G, Della Torre S, Luksch R, et al. 2004 Accuracy and clinical correlates of two different methods for chromogranin A assay in neuroendocrine tumors. International journal of Biological Markers 19 295-304. (https://doi.org/10.5301/JBM.2008.1664)

Ferrero E, Scabini S, Magni E, Foglieni C, Belloni D, Colombo B, Curnis F, Villa A, Ferrero ME \& Corti A 2004 Chromogranin A protects vessels against tumor necrosis factor alpha-induced vascular leakage. FASEB Journal 18 554-556.

Ferraro S, Borille S \& Panteghini M 2016 Reference intervals for the Kryptor second-generation chromogranin A assay. Clinical Chemistry and Laboratory Medicine 54 e335-e337.

Fiore F, Del Prete M, Franco R, Marotta V, Ramundo V, Marciello F, Di Sarno A, Carratu AC, de Luca di Roseto C, Colao A, et al. 2014 Transarterial embolization (TAE) is equally effective and slightly safer than transarterial chemoembolization (TACE) to manage liver metastases in neuroendocrine tumors. Endocrine 47 177-182. (https://doi.org/10.1007/s12020-013-0130-9)

Fossmark R, Jianu CS, Martinsen TC, Qvigstad G, Syversen U \& Waldum HL 2008 Serum gastrin and chromogranin A levels in patients with fundic gland polyps caused by long-term proton-pump inhibition. Scandinavian Journal of Gastroenterology 43 20-24. (https://doi.org/10.1080/00365520701561959)

Frilling A, Akerstrom G, Falconi M, Pavel M, Ramos J, Kidd M \& Modlin IM 2012 Neuroendocrine tumor disease: an evolving landscape. Endocrine-Related Cancer 19 R163-R185. (https://doi. org/10.1530/ERC-12-0024)

Gerdes HH, Phillips E \& Huttner WB 1988 The primary structure of rat secretogranin II deduced from a cDNA sequence. Nucleic Acids Research 16 11811. (https://doi.org/10.1093/nar/16.24.11811)

Giovanella L, Marelli M, Ceriani L, Giardina G, Garancini S \& Colombo L 2001 Evaluation of chromogranin A expression in serum and tissues of breast cancer patients. International journal of Biological Markers 16 268-272.

Glinicki P \& Jeske W 2011 Chromogranin A (CgA) - the influence of various factors in vivo and in vitro, and existing disorders on it's concentration in blood. Endokrynologia Polska $61384-387$.

Glinicki P, Jeske W, Kapuscinska R \& Zgliczynski W 2015 Comparison of chromogranin A (CgA) levels in serum and plasma (EDTA2K) and the respective reference ranges in healthy males. Endokrynologia Polska 66 53-56. (https://doi.org/10.5603/EP.2015.0009)

Gonzalez-Yanes C \& Sanchez-Margalet V 2000 Pancreastatin modulates insulin signaling in rat adipocytes: mechanisms of cross-talk. Diabetes 49 1288-1294. (https://doi.org/10.2337/diabetes.49.8.1288)

Goudet P, Murat A, Binquet C, Cardot-Bauters C, Costa A, Ruszniewski P, Niccoli P, Menegaux F, Chabrier G, Borson-Chazot F, et al. 2010 Risk factors and causes of death in MEN1 disease. A GTE (Groupe d'Etude des Tumeurs Endocrines) cohort study among 758 patients. World Journal of Surgery 34 249-255. (https://doi.org/10.1007/s00268-0090290-1)

Guignat L, Bidart JM, Nocera M, Comoy E, Schlumberger M \& Baudin E 2001 Chromogranin A and the alpha-subunit of glycoprotein hormones in medullary thyroid carcinoma and phaeochromocytoma. British Journal of Cancer $\mathbf{8 4} 808-812$. (https:// doi.org/10.1054/bjoc.2000.1677)

Gut P, Czarnywojtek A, Fischbach J, Baczyk M, Ziemnicka K, Wrotkowska E, Gryczynska M \& Ruchala M 2016 Chromogranin A - unspecific neuroendocrine marker. Clinical utility and potential diagnostic pitfalls. Archives of Medical Science 12 1-9. (https://doi. org/10.5114/aoms.2016.57577)

Helle KB \& Corti A 2015 Chromogranin A: a paradoxical player in angiogenesis and vascular biology. Cellular and Molecular Life Sciences 72 339-348. (https://doi.org/10.1007/s00018-014-1750-9) 
Hood L \& Tian Q 2012 Systems approaches to biology and disease enable translational systems medicine. Genomics Proteomics Bioinformatics 10 181-185. (https://doi.org/10.1016/j. gpb.2012.08.004)

Hoshino K, Suzuki J, Yamauchi K \& Inoue H 2008 Psychological stress evaluation of patients with bronchial asthma based on the chromogranin a level in saliva. Journal of Asthma 45 596-599. (https://doi.org/10.1080/02770900802126966)

Hsiao RJ, Mezger MS \& O'Connor DT 1990 Chromogranin A in uremia: progressive retention of immunoreactive fragments. Kidney International 37 955-964. (https://doi.org/10.1038/ki.1990.71)

Ichikawa T, Peterson MS, Federle MP, Baron RL, Haradome H, Kawamori Y, Nawano S \& Araki T 2000 Islet cell tumor of the pancreas: biphasic CT versus MR imaging in tumor detection. Radiology 216 163-171. (https://doi.org/10.1148/ radiology.216.1.r00j126163)

Janson ET, Holmberg L, Stridsberg M, Eriksson B, Theodorsson E, Wilander E \& Oberg K 1997 Carcinoid tumors: analysis of prognostic factors and survival in 301 patients from a referral center. Annals of Oncology 8 685-690. (https://doi.org/10.1023/A:1008215730767)

Jansson AM, Rosjo H, Omland T, Karlsson T, Hartford M, Flyvbjerg A \& Caidahl K 2009 Prognostic value of circulating chromogranin A levels in acute coronary syndromes. European Heart Journal 30 25-32. (https://doi.org/10.1093/eurheartj/ehn513)

Jensen RT, Cadiot G, Brandi ML, de Herder WW, Kaltsas G, Komminoth P, Scoazec JY, Salazar R, Sauvanet A \& Kianmanesh R 2012 ENETS Consensus Guidelines for the management of patients with digestive neuroendocrine neoplasms: functional pancreatic endocrine tumor syndromes. Neuroendocrinology 95 98-119. (https://doi.org/10.1159/000335591)

Jilesen AP, Busch OR, van Gulik TM, Gouma DJ \& Nieveen van Dijkum EJ 2014 Standard pre- and postoperative determination of chromogranin a in resectable non-functioning pancreatic neuroendocrine tumors - diagnostic accuracy: NF-pNET and low tumor burden. Digestive Surgery 31 407-414. (https://doi. org/10.1159/000370007)

Jun E, Kim SC, Song KB, Hwang DW, Lee JH, Shin SH, Hong SM, Park KM \& Lee YJ 2017 Diagnostic value of chromogranin A in pancreatic neuroendocrine tumors depends on tumor size: a prospective observational study from a single institute. Surgery 162 120-130.

Kaltsas GA, Besser GM \& Grossman AB 2004 The diagnosis and medical management of advanced neuroendocrine tumors. Endocrine Reviews 25 458-511. (https://doi.org/10.1210/er.2003-0014)

Kidd M, Bodei L \& Modlin IM 2016 Chromogranin A: any relevance in neuroendocrine tumors? Current Opinion in Endocrinology, Diabetes and Obesity 23 28-37. (https://doi.org/10.1097/ MED.0000000000000215)

Kim T, Gondre-Lewis MC, Arnaoutova I \& Loh YP 2006 Dense-core secretory granule biogenesis. Physiology 21 124-133. (https://doi. org/10.1152/physiol.00043.2005)

Kimura N, Miura W, Noshiro T, Mizunashi K, Hanew K, Shimizu K, Watanabe T, Shibukawa S, Sohn HE, Abe K, et al. 1997 Plasma chromogranin A in pheochromocytoma, primary hyperparathyroidism and pituitary adenoma in comparison with catecholamine, parathyroid hormone and pituitary hormones. Endocrine Journal 44 319-327. (https://doi.org/10.1507/ endocrj.44.319)

Kloppel G, Couvelard A, Perren A, Komminoth P, McNicol AM, Nilsson O, Scarpa A, Scoazec JY, Wiedenmann B, Papotti M, et al. 2009 ENETS Consensus Guidelines for the Standards of Care in Neuroendocrine Tumors: towards a standardized approach to the diagnosis of gastroenteropancreatic neuroendocrine tumors and their prognostic stratification. Neuroendocrinology 90 162-166. (https://doi. $\operatorname{org} / 10.1159 / 000182196)$
Konecki DS, Benedum UM, Gerdes HH \& Huttner WB 1987 The primary structure of human chromogranin A and pancreastatin. Journal of Biological Chemistry 262 17026-17030.

Korse CM, Taal BG, Vincent A, van Velthuysen ML, Baas P, BuningKager JC, Linders TC \& Bonfrer JM 2012 Choice of tumour markers in patients with neuroendocrine tumours is dependent on the histological grade. A marker study of chromogranin A, neuron specific enolase, progastrin-releasing peptide and cytokeratin fragments. European Journal of Cancer 48 662-671. (https://doi. org/10.1016/j.ejca.2011.08.012)

Koshimizu H, Kim T, Cawley NX \& Loh YP 2010 Chromogranin A: a new proposal for trafficking, processing and induction of granule biogenesis. Regulatory Peptides 160 153-159. (https://doi. org/10.1016/j.regpep.2009.12.007)

Kouvaraki MA, Ajani JA, Hoff P, Wolff R, Evans DB, Lozano R \& Yao JC 2004 Fluorouracil, doxorubicin, and streptozocin in the treatment of patients with locally advanced and metastatic pancreatic endocrine carcinomas. Journal of Clinical Oncology 22 4762-4771. (https://doi. org/10.1200/JCO.2004.04.024)

Kruger PG, Mahata SK \& Helle KB 2003 Catestatin (CgA344-364) stimulates rat mast cell release of histamine in a manner comparable to mastoparan and other cationic charged neuropeptides. Regulatory Peptides 114 29-35. (https://doi.org/10.1016/S0167-0115(03)00069-7)

Kuehn MJ, Herrmann JM \& Schekman R 1998 COPII-cargo interactions direct protein sorting into ER-derived transport vesicles. Nature 391 187-190. (https://doi.org/10.1038/34438)

Kuipers EJ 2006 Proton pump inhibitors and gastric neoplasia. Gut 55 1217-1221. (https://doi.org/10.1136/gut.2005.090514)

Kulke MH, Benson AB 3rd, Bergsland E, Berlin JD, Blaszkowsky LS, Choti MA, Clark OH, Doherty GM, Eason J, Emerson L, et al. 2012 Neuroendocrine tumors. Journal of the National Comprehensive Cancer Network 10 724-764. (https://doi.org/10.6004/jnccn.2012.0075)

Kulke MH, Shah MH, Benson AB 3rd, Bergsland E, Berlin JD, Blaszkowsky LS, Emerson L, Engstrom PF, Fanta P, Giordano T, et al. 2015 Neuroendocrine tumors, version 1.2015. Journal of the National Comprehensive Cancer Network 13 78-108. (https://doi.org/10.6004/ jnccn.2015.0011)

Kunz PL, Reidy-Lagunes D, Anthony LB, Bertino EM, Brendtro K, Chan JA, Chen H, Jensen RT, Kim MK, Klimstra DS, et al. 2013 Consensus guidelines for the management and treatment of neuroendocrine tumors. Pancreas 42 557-577. (https://doi. org/10.1097/MPA.0b013e31828e34a4)

Lamberts SW, Hofland LJ \& Nobels FR 2001 Neuroendocrine tumor markers. Frontiers in Neuroendocrinology 22 309-339. (https://doi org/10.1006/frne.2001.0218)

Langley K 1994 The neuroendocrine concept today. Annals of the New York Academy of Sciences 733 1-17. (https://doi org/10.1111/j.1749-6632.1994.tb17251.x)

Leon A, Torta M, Dittadi R, degli Uberti E, Ambrosio MR, Delle Fave G, De Braud F, Tomassetti P, Gion M \& Dogliotti L 2005 Comparison between two methods in the determination of circulating chromogranin A in neuroendocrine tumors (NETs): results of a prospective multicenter observational study. International journal of Biological Markers 20 156-168.

Leoncini E, Boffetta P, Shafir M, Aleksovska K, Boccia S \& Rindi G 2017 Increased incidence trend of low-grade and high-grade neuroendocrine neoplasms. Endocrine [epub]. (https://doi. org/10.1007/s12020-017-1273-x)

Lindholm DP \& Oberg K 2011 Biomarkers and molecular imaging in gastroenteropancreatic neuroendocrine tumors. Hormone and Metabolic Research 43 832-837. (https://doi. org/10.1055/s-0031-1287794)

Mahata SK, O'Connor DT, Mahata M, Yoo SH, Taupenot L, Wu H, Gill BM \& Parmer RJ 1997 Novel autocrine feedback control of catecholamine release. A discrete chromogranin a fragment is a 
noncompetitive nicotinic cholinergic antagonist. Journal of Clinical Investigation 100 1623-1633. (https://doi.org/10.1172/JCI119686)

Mahata SK, Mahata M, Wen G, Wong WB, Mahapatra NR, Hamilton BA \& O'Connor DT 2004 The catecholamine release-inhibitory 'catestatin' fragment of chromogranin a: naturally occurring human variants with different potencies for multiple chromaffin cell nicotinic cholinergic responses. Molecular Pharmacology 66 1180-1191. (https://doi.org/10.1124/mol.104.002139)

Mahata SK, Mahata M, Fung MM \& O'Connor DT 2010 Catestatin: a multifunctional peptide from chromogranin A. Regulatory Peptides 162 33-43. (https://doi.org/10.1016/j.regpep.2010.01.006)

Malaguarnera M, Cristaldi E, Cammalleri L, Colonna V, Lipari H, Capici A, Cavallaro A, Beretta M, Alessandria I, Luca S, et al. 2009 Elevated chromogranin A $(\mathrm{CgA})$ serum levels in the patients with advanced pancreatic cancer. Archives of Gerontology and Geriatrics 48 213-217. (https://doi.org/10.1016/j.archger.2008.01.014)

Marotta V, Nuzzo V, Ferrara T, Zuccoli A, Masone M, Nocerino L, Del Prete M, Marciello F, Ramundo V, Lombardi G, et al. 2012 Limitations of chromogranin A in clinical practice. Biomarkers 17 186-191. (https://doi.org/10.3109/1354750X.2012.654511)

Marotta V, Franzese MD, Del Prete M, Chiofalo MG, Ramundo V, Esposito R, Marciello F, Pezzullo L, Carratu A, Vitale M, et al. 2013 Targeted therapy with kinase inhibitors in aggressive endocrine tumors. Expert Opinion on Pharmacotherapy 14 1187-1203. (https://doi.org/10.1517/14656566.2013.796931)

Minamiki T, Minami T, Sasaki Y, Wakida SI, Kurita R, Niwa O \& Tokito S 2016 Label-free detection of human glycoprotein (CgA) using an extended-gated organic transistor-based immunosensor. Sensors 16 article 2033.

Modlin IM, Oberg K, Chung DC, Jensen RT, de Herder WW, Thakker RV, Caplin M, Delle Fave G, Kaltsas GA, Krenning EP, et al. 2008 Gastroenteropancreatic neuroendocrine tumours. Lancet Oncology 9 61-72. (https://doi.org/10.1016/S1470-2045(07)70410-2)

Modlin IM, Gustafsson BI, Moss SF, Pavel M, Tsolakis AV \& Kidd M 2010a Chromogranin A - biological function and clinical utility in neuro endocrine tumor disease. Annals of Surgical Oncology 17 2427-2443. (https://doi.org/10.1245/s10434-010-1006-3)

Modlin IM, Moss SF, Oberg K, Padbury R, Hicks RJ, Gustafsson BI, Wright NA \& Kidd M 2010b Gastrointestinal neuroendocrine (carcinoid) tumours: current diagnosis and management. Medical Journal of Australia 193 46-52.

Modlin IM, Drozdov I \& Kidd M 2013 The identification of gut neuroendocrine tumor disease by multiple synchronous transcript analysis in blood. PLOS ONE 8 e63364. (https://doi.org/10.1371/ journal.pone.0063364)

Modlin IM, Aslanian H, Bodei L, Drozdov I \& Kidd M 2014a A PCR blood test outperforms chromogranin A in carcinoid detection and is unaffected by proton pump inhibitors. Endocrine Connections $\mathbf{3}$ 215-223. (https://doi.org/10.1530/EC-14-0100)

Modlin IM, Drozdov I, Alaimo D, Callahan S, Teixiera N, Bodei L \& Kidd M 2014b A multianalyte PCR blood test outperforms single analyte ELISAs (chromogranin A, pancreastatin, neurokinin A) for neuroendocrine tumor detection. Endocrine-Related Cancer 21 615-628. (https://doi.org/10.1530/ERC-14-0190)

Modlin IM, Oberg K, Taylor A, Drozdov I, Bodei L \& Kidd M 2014 c Neuroendocrine tumor biomarkers: current status and perspectives. Neuroendocrinology 100 265-277. (https://doi.org/10.1159/000368363)

Modlin IM, Kidd M, Bodei L, Drozdov I \& Aslanian H 2015 The clinical utility of a novel blood-based multi-transcriptome assay for the diagnosis of neuroendocrine tumors of the gastrointestinal tract. American Journal of Gastroenterology 110 1223-1232. (https://doi. org/10.1038/ajg.2015.160)

Modlin IM, Frilling A, Salem RR, Alaimo D, Drymousis P, Wasan HS, Callahan S, Faiz O, Weng L, Teixeira N, et al. 2016 Blood measurement of neuroendocrine gene transcripts defines the effectiveness of operative resection and ablation strategies. Surgery 159 336-347. (https://doi.org/10.1016/j.surg.2015.06.056)

Molina R, Alvarez E, Aniel-Quiroga A, Borque M, Candas B, Leon A, Poyatos RM \& Gelabert M 2011 Evaluation of chromogranin A determined by three different procedures in patients with benign diseases, neuroendocrine tumors and other malignancies. Tumor Biology 32 13-22. (https://doi.org/10.1007/s13277-010-0085-x)

Mulkeen AL, Yoo PS \& Cha C 2006 Less common neoplasms of the pancreas. World Journal of Gastroenterology 12 3180-3185. (https://doi.org/10.3748/wjg.v12.i20.3180)

Nanno Y, Toyama H, Matsumoto I, Otani K, Asari S, Goto T, Ajiki T, Zen Y, Fukumoto T \& Ku Y 2017 Baseline plasma chromogranin A levels in patients with well-differentiated neuroendocrine tumors of the pancreas: A potential predictor of postoperative recurrence. Pancreatology 17 291-294. (https://doi.org/10.1016/j. pan.2016.12.012)

Nehar D, Lombard-Bohas C, Olivieri S, Claustrat B, Chayvialle JA, Penes MC, Sassolas G \& Borson-Chazot F 2004 Interest of Chromogranin A for diagnosis and follow-up of endocrine tumours. Clinical Endocrinology 60 644-652. (https://doi. org/10.1111/j.1365-2265.2004.02030.x)

Niederle B, Pape UF, Costa F, Gross D, Kelestimur F, Knigge U, Oberg K, Pavel M, Perren A, Toumpanakis C, et al. 2016 ENETS Consensus Guidelines update for neuroendocrine neoplasms of the jejunum and ileum. Neuroendocrinology 103 125-138. (https://doi. org/10.1159/000443170)

Niedworok C, Tschirdewahn S, Reis H, Lehmann N, Szucs M, Nyirady P, Romics I, Rubben H \& Szarvas T 2017 Serum chromogranin A as a complementary marker for the prediction of prostate cancer-specific survival. Pathology and Oncology Research 23 643-650. (https://doi. org/10.1007/s12253-016-0171-5)

Nikou GC, Marinou K, Thomakos P, Papageorgiou D, Sanzanidis V, Nikolaou P, Kosmidis C, Moulakakis A \& Mallas E 2008 Chromogranin a levels in diagnosis, treatment and follow-up of 42 patients with non-functioning pancreatic endocrine tumours. Pancreatology 8 510-519. (https://doi.org/10.1159/000152000)

Nobels FR, Kwekkeboom DJ, Coopmans W, Schoenmakers CH, Lindemans J, De Herder WW, Krenning EP, Bouillon R \& Lamberts SW 1997 Chromogranin A as serum marker for neuroendocrine neoplasia: comparison with neuron-specific enolase and the alpha-subunit of glycoprotein hormones. Journal of Clinical Endocrinology and Metabolism 82 2622-2628.

Nobels FR, Kwekkeboom DJ, Bouillon R \& Lamberts SW 1998 Chromogranin A: its clinical value as marker of neuroendocrine tumours. European Journal of Clinical Investigation 28 431-440. (https://doi.org/10.1046/j.1365-2362.1998.00305.x)

O'Connor DT \& Frigon RP 1984 Chromogranin A, the major catecholamine storage vesicle soluble protein. Multiple size forms, subcellular storage, and regional distribution in chromaffin and nervous tissue elucidated by radioimmunoassay. Journal of Biological Chemistry 259 3237-3247.

O'Connor DT, Pandlan MR, Carlton E, Cervenka JH \& Hslao RJ 1989 Rapid radioimmunoassay of circulating chromogranin A: in vitro stability, exploration of the neuroendocrine character of neoplasia, and assessment of the effects of organ failure. Clinical Chemistry $\mathbf{3 5}$ 1631-1637.

O’Toole D, Grossman A, Gross D, Delle Fave G, Barkmanova J, O'Connor J, Pape UF \& Plockinger U 2009 ENETS Consensus Guidelines for the standards of care in neuroendocrine tumors: biochemical markers. Neuroendocrinology 90 194-202.

Oberg K 2011 Circulating biomarkers in gastroenteropancreatic neuroendocrine tumours. Endocrine-Related Cancer 18 (Supplement 1) S17-S25. (https://doi.org/10.1530/ERC-10-0280)

Oberg K 2012 Neuroendocrine tumors of the digestive tract: impact of new classifications and new agents on therapeutic approaches. 
Current Opinion in Oncology 24 433-440. (https://doi.org/10.1097/ CCO.0b013e328353d7ba)

Oberg K, Akerstrom G, Rindi G \& Jelic S 2010 Neuroendocrine gastroenteropancreatic tumours: ESMO Clinical Practice Guidelines for diagnosis, treatment and follow-up. Annals of Oncology 21 (Supplement 5) v223-v227. (https://doi.org/10.1093/annonc/ mdq192)

Oberg K, Hellman P, Ferolla P \& Papotti M 2012a Neuroendocrine bronchial and thymic tumors: ESMO Clinical Practice Guidelines for diagnosis, treatment and follow-up. Annals of Oncology 23 (Supplement 7) vii120-vii123.

Oberg K, Knigge U, Kwekkeboom D \& Perren A 2012b Neuroendocrine gastro-entero-pancreatic tumors: ESMO Clinical Practice Guidelines for diagnosis, treatment and follow-up. Annals of Oncology 23 (Supplement 7) vii124-vii130.

Oberg K, Modlin IM, De Herder W, Pavel M, Klimstra D, Frilling A, Metz DC, Heaney A, Kwekkeboom D, Strosberg J, et al. 2015 Consensus on biomarkers for neuroendocrine tumour disease. Lancet Oncology 16 e435-e446. (https://doi.org/10.1016/S14702045(15)00186-2)

Paik WH, Ryu JK, Song BJ, Kim J, Park JK, Kim YT \& Yoon YB 2013 Clinical usefulness of plasma chromogranin a in pancreatic neuroendocrine neoplasm. Journal of Korean Medical Science 28 750754. (https://doi.org/10.3346/jkms.2013.28.5.750)

Panzuto F, Severi C, Cannizzaro R, Falconi M, Angeletti S, Pasquali A, Corleto VD, Annibale B, Buonadonna A, Pederzoli P, et al. 2004 Utility of combined use of plasma levels of chromogranin A and pancreatic polypeptide in the diagnosis of gastrointestinal and pancreatic endocrine tumors. Journal of Endocrinological Investigation 27 6-11. (https://doi.org/10.1007/BF03350903)

Pavel M, Baudin E, Couvelard A, Krenning E, Oberg K, Steinmuller T, Anlauf M, Wiedenmann B \& Salazar R 2012 ENETS Consensus Guidelines for the management of patients with liver and other distant metastases from neuroendocrine neoplasms of foregut, midgut, hindgut, and unknown primary. Neuroendocrinology 95 157-176. (https://doi.org/10.1159/000335597)

Pavel M, Jann H, Prasad V, Drozdov I, Modlin IM \& Kidd M 2017a NET blood transcript analysis defines the crossing of the clinical rubicon: when stable disease becomes progressive. Neuroendocrinology $\mathbf{1 0 4}$ 170-182. (https://doi.org/10.1159/000446025)

Pavel ME, Baudin E, Oberg KE, Hainsworth JD, Voi M, Rouyrre N, Peeters M, Gross DJ \& Yao JC $2017 b$ Efficacy of everolimus plus octreotide LAR in patients with advanced neuroendocrine tumor and carcinoid syndrome: final overall survival from the randomized, placebo-controlled phase 3 RADIANT-2 study. Annals of Oncology.

Pavel ME, Hainsworth JD, Baudin E, Peeters M, Horsch D, Winkler RE, Klimovsky J, Lebwohl D, Jehl V, Wolin EM, et al. 2011 Everolimus plus octreotide long-acting repeatable for the treatment of advanced neuroendocrine tumours associated with carcinoid syndrome (RADIANT-2): a randomised, placebo-controlled, phase 3 study. Lancet 378 2005-2012. (https://doi.org/10.1016/S01406736(11)61742-X)

Peracchi M, Conte D, Gebbia C, Penati C, Pizzinelli S, Arosio M, Corbetta S \& Spada A 2003 Plasma chromogranin A in patients with sporadic gastro-entero-pancreatic neuroendocrine tumors or multiple endocrine neoplasia type 1. European Journal of Endocrinology 148 39-43. (https://doi.org/10.1530/eje.0.1480039)

Peracchi M, Gebbia C, Basilisco G, Quatrini M, Tarantino C, Vescarelli C, Massironi S \& Conte D 2005 Plasma chromogranin A in patients with autoimmune chronic atrophic gastritis, enterochromaffin-like cell lesions and gastric carcinoids. European Journal of Endocrinology 152 443-448. (https://doi.org/10.1530/eje.1.01862)

Pieterman CR, Schreinemakers JM, Koppeschaar HP, Vriens MR, Rinkes IH, Zonnenberg BA, van der Luijt RB \& Valk GD 2009 Multiple endocrine neoplasia type 1 (MEN1): its manifestations and effect of genetic screening on clinical outcome. Clinical Endocrinology 70 575-581. (https://doi.org/10.1111/j.1365-2265.2008.03324.x)

Popovici T, Moreira B, Schlageter MH \& Bories PN 2014 Automated twosite immunofluorescent assay for the measurement of serum chromogranin A. Clinical Biochemistry 47 87-91. (https://doi. org/10.1016/j.clinbiochem.2013.10.029)

Qiu W, Christakis I, Silva A, Bassett RL Jr, Cao L, Meng QH, Gardner Grubbs E, Zhao H, Yao JC, Lee JE, et al. 2016 Utility of chromogranin A, pancreatic polypeptide, glucagon and gastrin in the diagnosis and follow-up of pancreatic neuroendocrine tumours in multiple endocrine neoplasia type 1 patients. Clinical Endocrinology 85 400-407. (https://doi.org/10.1111/cen.13119)

Ramage JK, Ahmed A, Ardill J, Bax N, Breen DJ, Caplin ME, Corrie P, Davar J, Davies AH, Lewington V, et al. 2012 Guidelines for the management of gastroenteropancreatic neuroendocrine (including carcinoid) tumours (NETs). Gut 61 6-32. (https://doi.org/10.1136/ gutjnl-2011-300831)

Ramundo V, Milone F, Severino R, Savastano S, Di Somma C, Vuolo L, De Luca L, Lombardi G, Colao A \& Faggiano A 2011 Clinical and prognostic implications of the genetic diagnosis of hereditary NET syndromes in asymptomatic patients. Hormone and Metabolic Research 43 794-800. (https://doi.org/10.1055/s-0031-1286324)

Ramundo V, Del Prete M, Marotta V, Marciello F, Camera L, Napolitano V, De Luca L, Circelli L, Colantuoni V, Di Sarno A, et al. 2014 Impact of long-acting octreotide in patients with early-stage MEN1-related duodeno-pancreatic neuroendocrine tumours. Clinical Endocrinology 80 850-855. (https://doi.org/10.1111/cen.12411)

Ruszniewski P, Delle Fave G, Cadiot G, Komminoth P, Chung D, KosKudla B, Kianmanesh R, Hochhauser D, Arnold R, Ahlman H, et al. 2006 Well-differentiated gastric tumors/carcinomas.

Neuroendocrinology 84 158-164. (https://doi.org/10.1159/000098007)

Sanchez-Margalet V, Calvo JR \& Goberna R 1992a Glucogenolytic and hyperglycemic effect of 33-49 C-terminal fragment of pancreastatin in the rat in vivo. Hormone and Metabolic Research 24 455-457. (https://doi.org/10.1055/s-2007-1003361)

Sanchez-Margalet V, Calvo JR, Lucas M \& Goberna R 1992b Pancreastatin and its 33-49 C-terminal fragment inhibit glucagonstimulated insulin in vivo. General Pharmacology 23 637-638. (https://doi.org/10.1016/0306-3623(92)90140-F)

Sanchez-Margalet V, Gonzalez-Yanes C, Najib S \& Santos-Alvarez J 2010 Metabolic effects and mechanism of action of the chromogranin A-derived peptide pancreastatin. Regulatory Peptides 161 8-14. (https://doi.org/10.1016/j.regpep.2010.02.005)

Sciola V, Massironi S, Conte D, Caprioli F, Ferrero S, Ciafardini C, Peracchi M, Bardella MT \& Piodi L 2009 Plasma chromogranin a in patients with inflammatory bowel disease. Inflammatory Bowel Diseases 15 867-871. (https://doi.org/10.1002/ibd.20851)

Shapiro DE 1999 The interpretation of diagnostic tests. Statistical Methods in Medical Research 8 113-134. (https://doi. org/10.1177/096228029900800203)

Sidhu R, McAlindon ME, Leeds JS, Skilling J \& Sanders DS 2009 The role of serum chromogranin A in diarrhoea predominant irritable bowel syndrome. Journal of Gastrointestinal and Liver Diseases 18 23-26.

Singhi AD, Chu LC, Tatsas AD, Shi C, Ellison TA, Fishman EK, Kawamoto S, Schulick RD, Wolfgang CL, Hruban RH, et al. 2012 Cystic pancreatic neuroendocrine tumors: a clinicopathologic study. American Journal of Surgical Pathology 36 1666-1673. (https://doi. org/10.1097/PAS.0b013e31826a0048)

Sobol RE, O'Connor DT, Addison J, Suchocki K, Royston I \& Deftos LJ 1986 Elevated serum chromogranin A concentrations in small-cell lung carcinoma. Annals of Internal Medicine 105 698-700. (https://doi.org/10.7326/0003-4819-105-5-698)

Solcia E, Kloppel G \& Sobin LH 2000 Histological Typing of Endocrine Tumours. WHO. World Health Organization. International Histological Classification of Tumours. Geneva, Switzerland: WHO. 
Spadaro A, Ajello A, Morace C, Zirilli A, D'Arrigo G, Luigiano C, Martino F, Bene A, Migliorato D, Turiano S, et al. 2005 Serum chromogranin-A in hepatocellular carcinoma: diagnostic utility and limits. World Journal of Gastroenterology 11 1987-1990. (https://doi. org/10.3748/wig.v11.i13.1987)

Stridsberg M, Eriksson B, Oberg K \& Janson ET 2003 A comparison between three commercial kits for chromogranin A measurements. Journal of Endocrinology 177 337-341. (https://doi.org/10.1677/ joe.0.1770337)

Sundin A, Vullierme MP, Kaltsas G \& Plockinger U 2009 ENETS Consensus Guidelines for the Standards of Care in Neuroendocrine Tumors: radiological examinations. Neuroendocrinology 90 167-183. (https://doi.org/10.1159/000184855)

Syversen U, Halvorsen T, Marvik R \& Waldum HL 1995 Neuroendocrine differentiation in colorectal carcinomas. European Journal of Gastroenterology and Hepatology 7 667-674.

Takiyyuddin MA, Baron AD, Cervenka JH, Barbosa JA, Neumann HP, Parmer RJ, Sullivan PA \& O'Connor DT 1991 Suppression of chromogranin-A release from neuroendocrine sources in man: pharmacological studies. Journal of Clinical Endocrinology and Metabolism 72 616-622. (https://doi.org/10.1210/jcem-72-3-616)

Takiyyuddin MA, Parmer RJ, Kailasam MT, Cervenka JH, Kennedy B, Ziegler MG, Lin MC, Li J, Grim CE, Wright FA, et al. 1995 Chromogranin A in human hypertension. Influence of heredity. Hypertension 26 213-220. (https://doi.org/10.1161/01.HYP.26.1.213)

Tatemoto K, Efendic S, Mutt V, Makk G, Feistner GJ \& Barchas JD 1986 Pancreastatin, a novel pancreatic peptide that inhibits insulin secretion. Nature 324 476-478. (https://doi.org/10.1038/324476a0)

Thakker RV, Newey PJ, Walls GV, Bilezikian J, Dralle H, Ebeling PR, Melmed S, Sakurai A, Tonelli F \& Brandi ML 2012 Clinical practice guidelines for multiple endocrine neoplasia type 1 (MEN1). Journal of Clinical Endocrinology and Metabolism 97 2990-3011. (https://doi. org/10.1210/jc.2012-1230)

Tohmola N, Itkonen O, Sane T, Markkanen H, Joenvaara S, Renkonen R \& Hamalainen E 2014 Analytical and preanalytical validation of a new mass spectrometric serum 5-hydroxyindoleacetic acid assay as neuroendocrine tumor marker. Clinica Chimica Acta 428 38-43. (https://doi.org/10.1016/j.cca.2013.10.025)

Tomassetti P, Migliori M, Lalli S, Campana D, Tomassetti V \& Corinaldesi R 2001a Epidemiology, clinical features and diagnosis of gastroenteropancreatic endocrine tumours. Annals of Oncology 12 (Supplement 2) S95-S99. (https://doi.org/10.1093/annonc/12. suppl_2.S95)

Tomassetti P, Migliori M, Simoni P, Casadei R, De Iasio R, Corinaldesi R $\&$ Gullo L $2001 b$ Diagnostic value of plasma chromogranin A in neuroendocrine tumours. European Journal of Gastroenterology and Hepatology 13 55-58. (https://doi.org/10.1097/00042737-20010100000010)

Van der Knaap RHP, Kwekkeboom DJ, Ramakers CRB \& de Rijke CRB 2015 Evaluation of a new immunoassay for chromogranin A measurement on the Kryptor syste. Practical Laboratory Medicine $\mathbf{1}$ 5-11. (https://doi.org/10.1016/j.plabm.2015.03.002)

van der Zwan WA, Bodei L, Mueller-Brand J, de Herder WW, Kvols LK \& Kwekkeboom DJ 2015 GEPNETs update: radionuclide therapy in neuroendocrine tumors. European Journal of Endocrinology 172 R1-R8. (https://doi.org/10.1530/EJE-14-0488)

Vezzosi D, Walter T, Laplanche A, Raoul JL, Dromain C, Ruszniewski P, d'Herbomez M, Guigay J, Mitry E, Cadiot G, et al. 2011 Chromogranin A measurement in metastatic well-differentiated gastroenteropancreatic neuroendocrine carcinoma: screening for false positives and a prospective follow-up study. International journal of Biological Markers 26 94-101. (https://doi.org/10.5301/ JBM.2011.8327)

Waldum HL, Arnestad JS, Brenna E, Eide I, Syversen U \& Sandvik AK 1996 Marked increase in gastric acid secretory capacity after omeprazole treatment. Gut 39 649-653. (https://doi.org/10.1136/ gut.39.5.649)

Walter T, Chardon L, Chopin-laly X, Raverot V, Caffin AG, Chayvialle JA, Scoazec JY \& Lombard-Bohas C 2012 Is the combination of chromogranin A and pancreatic polypeptide serum determinations of interest in the diagnosis and follow-up of gastro-entero-pancreatic neuroendocrine tumours? European Journal of Cancer 48 1766-1773. (https://doi.org/10.1016/j. ejca.2011.11.005)

Welin S, Stridsberg M, Cunningham J, Granberg D, Skogseid B, Oberg K, Eriksson B \& Janson ET 2009 Elevated plasma chromogranin A is the first indication of recurrence in radically operated midgut carcinoid tumors. Neuroendocrinology 89 302-307. (https://doi. org/10.1159/000179900

West NE, Wise PE, Herline AJ, Muldoon RL, Chopp WV \& Schwartz DA 2007 Carcinoid tumors are 15 times more common in patients with Crohn's disease. Inflammatory Bowel Diseases 13 1129-1134. (https://doi.org/10.1002/ibd.20172)

Winkler H \& Fischer-Colbrie R 1992 The chromogranins A and B: the first 25 years and future perspectives. Neuroscience 49 497-528. (https://doi.org/10.1016/0306-4522(92)90222-N)

Wolf M, Riedlinger I, Lehmann R, Haring HU, Schleicher E \& Peter A 2014 Comparison of the automated KRYPTOR chromogranin A assay with the DAKO ELISA. Clinical Laboratory 60 2103-2106. (https://doi. org/10.7754/Clin.Lab.2014.140422)

Woltering EA, Hilton RS, Zolfoghary CM, Thomson J, Zietz S, Go VL, Vinik AI, Vinik E, O'Dorisio TM \& Mamikunian G 2006 Validation of serum versus plasma measurements of chromogranin a levels in patients with carcinoid tumors: lack of correlation between absolute chromogranin a levels and symptom frequency. Pancreas 33 250-254. (https://doi.org/10.1097/01.mpa.0000235302.73615.d4)

Yao JC, Hassan M, Phan A, Dagohoy C, Leary C, Mares JE, Abdalla EK, Fleming JB, Vauthey JN, Rashid A, et al. 2008a One hundred years after 'carcinoid': epidemiology of and prognostic factors for neuroendocrine tumors in 35,825 cases in the United States. Journal of Clinical Oncology 26 3063-3072. (https://doi.org/10.1200/ JCO.2007.15.4377)

Yao JC, Phan AT, Chang DZ, Wolff RA, Hess K, Gupta S, Jacobs C, Mares JE, Landgraf AN, Rashid A, et al. 2008b Efficacy of RAD001 (everolimus) and octreotide LAR in advanced low- to intermediategrade neuroendocrine tumors: results of a phase II study. Journal of Clinical Oncology 26 4311-4318. (https://doi.org/10.1200/ JCO.2008.16.7858)

Yao JC, Lombard-Bohas C, Baudin E, Kvols LK, Rougier P, Ruszniewski P, Hoosen S, St Peter J, Haas T, Lebwohl D, et al. 2010 Daily oral everolimus activity in patients with metastatic pancreatic neuroendocrine tumors after failure of cytotoxic chemotherapy: a phase II trial. Journal of Clinical Oncology 28 69-76. (https://doi. org/10.1200/JCO.2009.24.2669)

Yao JC, Pavel M, Phan AT, Kulke MH, Hoosen S, St Peter J, Cherfi A \& Oberg KE 2011a Chromogranin A and neuron-specific enolase as prognostic markers in patients with advanced pNET treated with everolimus. Journal of Clinical Endocrinology and Metabolism 96 3741-3749. (https://doi.org/10.1210/jc.2011-0666)

Yao JC, Shah MH, Ito T, Bohas CL, Wolin EM, Van Cutsem E, Hobday TJ, Okusaka T, Capdevila J, de Vries EG, et al. 2011b Everolimus for advanced pancreatic neuroendocrine tumors. New England Journal of Medicine 364 514-523. (https://doi.org/10.1056/ NEJMoa1009290)

Yao JC, Pavel M, Lombard-Bohas C, Van Cutsem E, Voi M, Brandt U, He W, Chen D, Capdevila J, de Vries EG, et al. 2016 Everolimus for the treatment of advanced pancreatic neuroendocrine tumors: overall survival and circulating biomarkers from the randomized, phase III RADIANT-3 study. Journal of Clinical Oncology [epub]. (https://doi.org/10.1200/JCO.2016.68.0702) 
Yao JC, Voi M, Lincy J \& Pavel M 2017 Reply to V. Amoroso et al. Journal of Clinical Oncology 35 1488-1489. (https://doi.org/10.1200/ JCO.2017.71.3875)

Yoo SH 2010 Secretory granules in inositol 1,4,5-trisphosphatedependent $\mathrm{Ca} 2+$ signaling in the cytoplasm of neuroendocrine cells. FASEB Journal 24 653-664. (https://doi.org/10.1096/fj.09132456)

Yoo SH, Huh YH \& Hur YS 2010 Inositol 1,4,5-trisphosphate receptor in chromaffin secretory granules and its relation to chromogranins. Cellular and Molecular Neurobiology 30 1155-1161. (https://doi. org/10.1007/s10571-010-9564-2)
Zatelli MC, Torta M, Leon A, Ambrosio MR, Gion M, Tomassetti P, De Braud F, Delle Fave G, Dogliotti L \& degli Uberti EC 2007 Chromogranin A as a marker of neuroendocrine neoplasia: an Italian Multicenter Study. Endocrine-Related Cancer 14 473-482. (https://doi. org/10.1677/ERC-07-0001)

Zhang D, Shooshtarizadeh P, Laventie BJ, Colin DA, Chich JF, Vidic J, de Barry J, Chasserot-Golaz S, Delalande F, Van Dorsselaer A, et al. 2009 Two chromogranin a-derived peptides induce calcium entry in human neutrophils by calmodulin-regulated calcium independent phospholipase A2. PLOS ONE 4 e4501. (https://doi.org/10.1371/ journal.pone.0004501)

Received in final form 12 October 2017

Accepted 24 October 2017

Accepted Preprint published online 24 October 2017 